\title{
A Modified Elastic Foundation Beam Method for Analyzing Lateral Wall Deformation in Excavations with Cross Wall
}

\author{
Bo Li $\left(\mathbb{D},{ }^{1}\right.$ Guihe Wang $\left(\mathbb{D},{ }^{1}\right.$ Cangqin Jia $\mathbb{D}^{1},{ }^{1}$ Jun Ren $\left(\mathbb{D},{ }^{2}\right.$ Gaofeng Lu $\left(\mathbb{D},{ }^{3}\right.$ and Nannan Liu $\left(\mathbb{D}{ }^{4}\right.$ \\ ${ }^{1}$ School of Engineering and Technology, China University of Geosciences (Beijing), Haidian District, Beijing 100083, China \\ ${ }^{2}$ CCCC Tunnel Engineering Company Limited, Chaoyang District, Beijing 100102, China \\ ${ }^{3}$ Beijing Metro Construction Administration Corporation Ltd, Fengtai District, Beijing 100068, China \\ ${ }^{4}$ School of Energy Resources, China University of Geosciences (Beijing), Haidian District, Beijing 100083, China \\ Correspondence should be addressed to Guihe Wang; wanggh@cugb.edu.cn
}

Received 13 April 2020; Revised 10 June 2021; Accepted 2 July 2021; Published 26 July 2021

Academic Editor: Hui Yao

Copyright $\odot 2021 \mathrm{Bo}$ Li et al. This is an open access article distributed under the Creative Commons Attribution License, which permits unrestricted use, distribution, and reproduction in any medium, provided the original work is properly cited.

\begin{abstract}
Cross walls have been used as alternative auxiliary measures to protect buildings in some areas of Asia. Realizing the inadequacy of the classical Winkler foundation to predict the deflection of the diaphragm wall with cross wall, a modified Winkler foundation of the finite element method (MEFB) was formulated in this paper. Then, the MEFB method was verified through two excavation cases and applied in a new well-documented excavation history. Results showed that the wall deflection by the proposed method was line with the 3D numerical analysis and field observations but smaller than that of classical Winkler's elastic foundation (EFB) method. The maximum deformation calculated by the MEFB method was predicted to have a reduction of 40 60\% compared to those of the EFB method. Meanwhile, the wall deformation was minimum at the location of cross walls and reaches the maximum value at the midline between two cross walls. Besides, the plane strain ratio $\left(\mathrm{PSR}_{d}\right)$ based on the MEFB method was defined to study the interval $(L)$, the embedded depth, and arrangement of cross walls. The results indicated the MEFB method was used successfully as a more accurate method than Winkler foundation and is simpler than 3D numerical analysis method for the engineering design of the diaphragm-cross wall system during excavation.
\end{abstract}

\section{Introduction}

The analysis of beams and plates on elastic foundations is widespread in excavation engineering [1-6]. While material properties of the beam or slab can be established fairly accurately, the characteristics or parameters that represent the behavior of the subsoil or the elastic foundation are difficult to model. Under such circumstances, various deformation theories for the wall and beam structures were proposed. Researchers like Vlasov and Leont'ev [7] introduced an arbitrary parameter, $\gamma$, to characterize the distribution of the vertical displacement in an elastic foundation. Jones and Xenophontos [8], using variational principles, strengthened the Vlasov model by establishing a relationship between the $\gamma$ parameter and the displacement of the beam or slab on the top. Vallabhan and Das [9] developed a simple iterative procedure to determine the $\gamma$ parameter; this procedure is referred to herein as a "modified" or "refined Vlasov model." Winkler [10] represented the vertical deformation characteristics of the elastic foundation by means of continuous linear springs. The constant of proportionality of these springs is known as the "modulus of subgrade reaction," usually represented by $k$. The calculation of $k$ is very simple if the soil behavior is linear, homogeneous, and isotropic. However, when the reinforcement condition existed in the foundation soil, the formula of $k$ in Winkler hypothesis is no longer applicable.

Recently, the diaphragm wall with cross walls was applied as a novel retaining structure system to reduce wall deformation in some areas of Asia [11-16]. As shown in Figure 1, cross walls were constructed perpendicularly to the diaphragm wall using the same diaphragm wall construction technique. Unlike traditional steel struts being installed after excavation, cross walls were constructed before excavation. 


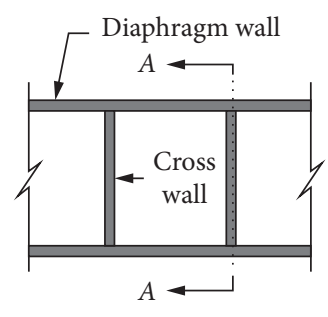

(a)

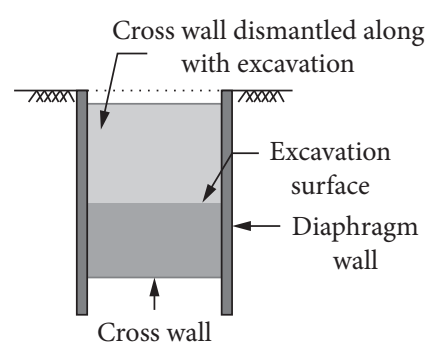

(b)

Figure 1: Schematic diagram of the cross wall: (a) plan view; (b) section A-A.

Due to the high compressive strength and large axial stiffness of cross walls, the diaphragm wall deformation was highly restrained.

In this paper, an attempt was made to consider the effect of cross wall on restraining diaphragm wall deflection, and Winkler's elastic foundation was modified for the solution of practical problems. First, for this modified Winkler's model, the modulus of subgrade reaction $k$ was modified by structural mechanics and superposition principle. Second, the finite difference method is the numerical technique used herein to solve the differential equations. Results obtained from using modified model are compared with Winkler's model and field observations, as well as more sophisticated finite element solutions. The comparison results prove that the modified Winker model is more suitable to predict the diaphragm wall deflection with cross walls.

\section{Theoretical Analysis}

2.1. Winkler Foundation. The diaphragm wall can be regarded as a vertical plate of elastic foundation with springs, as shown in Figure 2(a). The later supports and passive earth pressure were simplified as horizontal spring elements. Figure 2(b) shows a microsegment with unit width in the $x$ direction extracted from the diaphragm wall. According to the theory of structural mechanics, the differential equation was obtained by the following equation:

$$
V+k_{h} y \mathrm{~d} x-q \mathrm{~d} x-(V+\mathrm{d} V)=0 .
$$

Based on the Euler-Bernoulli beam calculation theory, the differential equation of the diaphragm wall could be calculated by the following equation:

$$
\mathrm{EI} \frac{\mathrm{d}^{4} y}{\mathrm{~d} x^{4}}+k_{h} y=q(y),
$$

where EI is the bending stiffness of the retaining wall and $k_{h}$ is the stiffness coefficient of the earth spring. For the part above the excavation surface, $k_{h}=0 . q(y)$ was the horizontal load function on the wall. The spring stiffness coefficient $k_{h}$ can be expressed by [17]

$$
k_{h}=m a b h,
$$

where $m$ is a proportionality factor; $a, b$ are the calculated spacings of the passive soil spring, respectively; and $h$ is the calculating point to the excavation surface.
2.2. Modification of $k_{h}$. Different from the floor slab, the cross wall was usually inserted into the foundation soil before excavation. Therefore, the spring stiffness coefficient $k_{h}$ need to be modified. According to the behavior of a continuous beam in structural mechanics, the deformation of the diaphragm-cross wall was plotted as shown in Figure 3.

Based on the superposition principle, the wall deformation in the analysis block could be divided into a simply supported beam with a constant deformation $\left(\delta_{d_{0}}\right)$ and a fixed beam with a variety of deformation $\left(\Delta \delta_{d}\right)$, as shown in (A) in Figure 4(b) and (A) in Figure 4(c), respectively. The total deformation $\left(\delta_{d_{0}}\right)$ of the diaphragm-cross wall $((\mathrm{A})$ in Figure $4(\mathrm{a})$ ) at any point away from the cross wall can be given by

$$
\delta_{d}=\delta_{d_{0}}+\Delta \delta_{d}
$$

Under the uniform pressure, the deformation of the fixed beam can be calculated by

$$
\Delta \delta_{d}=\frac{q L^{2} d^{2}}{24 E_{w} I_{w}}\left(1-\frac{2 d}{L^{2}}+\frac{d^{2}}{L^{2}}\right) .
$$

The resistance of the simply supported beam can be converted into a kind of earth spring with equal rigidity $K_{\mathrm{CW}}$ which is calculated by equation (6) [17], as shown in (B) in Figure 4(b). Similarly, the resistance of fix end beam can be converted into a kind of earth spring with varying stiffness $K_{w . d}((\mathrm{~B})$ in Figure $4(\mathrm{c})$ ), which is calculated by

$$
\begin{aligned}
& k_{\mathrm{cw}}=\frac{2 \alpha \mathrm{AE}_{\mathrm{cw}}}{B L_{\mathrm{cw}}}, \\
& k_{w, d}=\frac{q}{\Delta \delta_{d}},
\end{aligned}
$$

where $E_{\mathrm{cw}}$ is the elastic modulus of the cross wall; $\alpha$ is a reduction coefficient related to support relaxation (generally $0.5 \sim 1.0) ; A$ is the calculation unit cross-sectional area; $B$ is the excavation width; $L_{\mathrm{cw}}$ is the cross wall interval; $E_{w} I_{w}$ is the bending stiffness of the diaphragm wall; $q$ is the uniform pressure; and $d$ is the distance to the cross wall.

According to equation (4), the unit rigidity of the diaphragm-cross wall system $K_{e, d}$ was obtained as the following expression: 


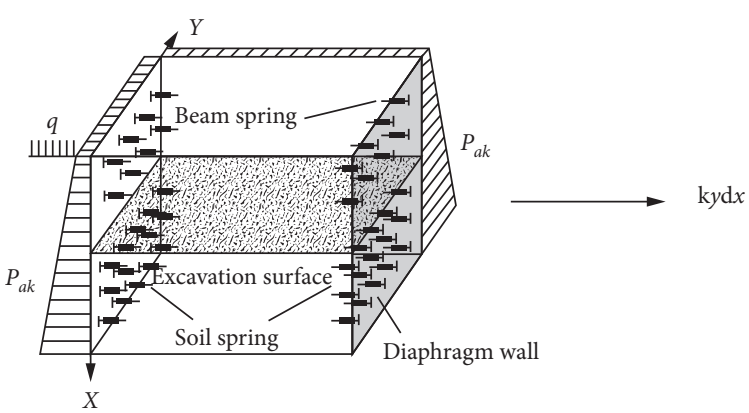

(a)

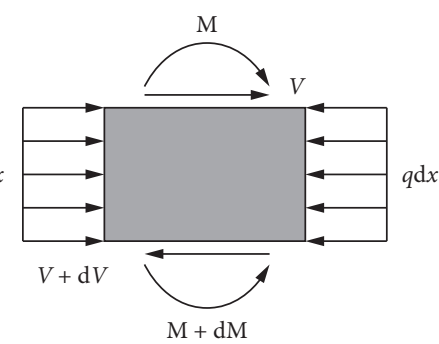

(b)

FIGURE 2: Mechanical model of the elastic foundation beam. (a) The retaining system. (b) Basic element.

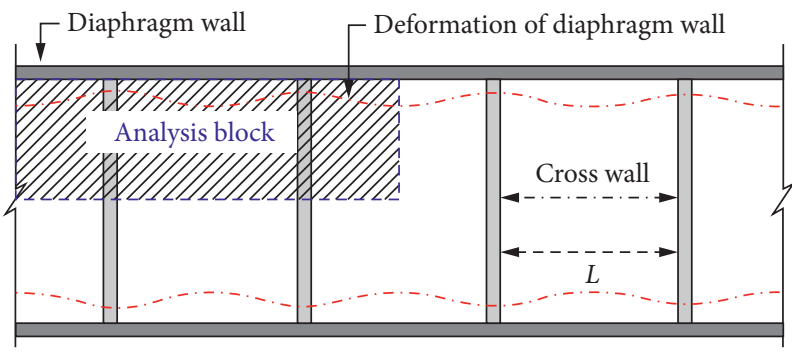

Figure 3: Deformation of the diaphragm-cross wall system.

$$
k_{e, d}=\frac{k_{w, d} k_{\mathrm{cw}}}{k_{w, d}+k_{\mathrm{cw}}} .
$$

Then, the stiffness coefficient of $k_{h}$ per unit depth and per unit length can be modified to $k_{d}$ as follows :

$$
k_{d}=k_{e, d} h+k_{h} \text {. }
$$

The behavior could be explained as multiple sets of parallel springs, that is, at the same height of the excavation, the earth pressure outside the pit was resisted by the stiffness of the soil spring and the stiffness of the cross wall.

\subsection{Finite Element Calculation}

2.3.1. Beam Element Stiffness Matrix. Figure 5(a) shows a beam with length $L$ and bending stiffness EI which was assumed to have a horizontal force $P_{i}(i=1,2 \ldots n)$ and concentrated moment $M_{i}(i=1,2 \ldots n)$. The beam can be discretized into finite elements of length $l$ as shown in Figure 5(b). The boundary conditions were obtained as follows:

$$
\begin{aligned}
& \delta_{x=0}=0, \\
& \theta_{x=o}=\left(\frac{d_{\delta}}{d_{x}}\right)_{x=0}=0,
\end{aligned}
$$

$$
\begin{aligned}
& M_{(x=L)}=\left.\mathrm{EI} \frac{\mathrm{d}^{2} v}{\mathrm{~d} x^{2}}\right|_{x=l}=M_{1}, \\
& F_{(x=L)}=\left.\frac{\mathrm{d}}{\mathrm{d} x}\left\{\mathrm{EI} \frac{\mathrm{d}^{2} v}{\mathrm{~d} x^{2}}\right\}\right|_{x=l}=P_{1} .
\end{aligned}
$$

In the local coordinate system, $u, v$, and $\varphi$ are used to represent the node displacements of $i$ and $j$, respectively, and the node force component is represented by $X, Y$, and $M$, as shown in Figures 5(c) and 5(d). The element stiffness matrix of beam element in the local coordinate system is expressed as follows:

$$
\begin{aligned}
& \left\{f^{\prime}\right\}=\left[K_{B}^{\prime}\right]\left\{\delta^{\prime}\right\}, \\
& \left\{f^{\prime}\right\}=\left\{\begin{array}{c}
\left\{f_{i j}^{\prime}\right\} \\
\left\{f_{i j}^{\prime}\right\}
\end{array}\right\}=\left(\begin{array}{llllll}
X_{i}^{\prime} & Y_{i}^{\prime} & M_{i}^{\prime} & X_{j}^{\prime} & Y_{j}^{\prime} & M_{j}^{\prime}
\end{array}\right)^{T},
\end{aligned}
$$

$$
\left\{\delta^{\prime}\right\}=\left\{\begin{array}{c}
\left\{\delta_{i}^{\prime}\right\} \\
\left\{\delta_{j}^{\prime}\right\}
\end{array}\right\}=\left(\begin{array}{llllll}
u_{i}^{\prime} & v_{i}^{\prime} & \phi_{i}^{\prime} & u_{j}^{\prime} & v_{j}^{\prime} & \phi_{j}^{\prime}
\end{array}\right)^{T}
$$




$$
\left[K_{B}^{\prime}\right]=\left[\begin{array}{cccccc}
\frac{\mathrm{EA}}{l} & 0 & 0 & -\frac{\mathrm{EA}}{l} & 0 & 0 \\
0 & 12 \frac{\mathrm{EI}}{l^{3}} & 6 \frac{\mathrm{EI}}{l^{2}} & 0 & -12 \frac{\mathrm{EI}}{l^{3}} & 6 \frac{\mathrm{EI}}{l^{2}} \\
0 & 6 \frac{\mathrm{EI}}{l^{2}} & 4 \frac{\mathrm{EA}}{l} & 0 & -6 \frac{\mathrm{EI}}{l^{2}} & 2 \frac{\mathrm{EA}}{l} \\
-\frac{\mathrm{EA}}{l} & 0 & 0 & \frac{\mathrm{EA}}{l} & 0 & 0 \\
0 & -12 \frac{\mathrm{EI}}{l^{3}} & -6 \frac{\mathrm{EI}}{l^{2}} & 0 & 12 \frac{\mathrm{EI}}{l^{3}} & -6 \frac{\mathrm{EI}}{l^{2}} \\
0 & 6 \frac{\mathrm{EI}}{l^{2}} & 2 \frac{\mathrm{EA}}{l} & 0 & -6 \frac{\mathrm{EI}}{l^{2}} & 4 \frac{\mathrm{EA}}{l}
\end{array}\right],
$$

where $\left[K_{B}^{\prime}\right]$ is the stiffness matrix of foundation beam in the local coordinate system; $[\delta]$ is the node displacement matrix in the local coordinate system; and $\left\{f^{\prime}\right\}$ is the node load array in the local coordinate system.

2.3.2. Spring Element Stiffness Matrix. The spring element in the local coordinate system is shown in Figure 6. One end of spring element $i$ is fixed, and the other end is connected with node $i$ of the beam element. The action range of spring element $i$ is a rectangular area with length $l$ and width $b$.

According to the basic mechanical equation of Winkler's foundation beam, the stiffness matrix $K_{s}^{i}$ is obtained as the following expression:

$$
\left[K_{S}^{\prime}\right]=\left[\begin{array}{ccc}
k_{s}^{\prime} l b & 0 & 0 \\
0 & 0 & 0 \\
0 & 0 & 0
\end{array}\right] .
$$

For the anchor structure above the excavation surface, the stiffness coefficient $k_{s}$ is calculated as follows [17]:

$$
k_{s}=\frac{E A}{L} .
$$

For the stiffness of the passive zone below the excavation surface, the stiffness coefficient $k_{s}$ is replaced by $k_{d}$ as in equation (9).

2.3.3. Load Array. When the element $i j$ with length $l$ is subjected to uniformly distributed load $q$, the equivalent nodal load array in the local coordinate system is as follows:

$$
\left\{F_{i j}^{\prime}\right\}=\left\{0 \frac{-q l}{2} \frac{-q l^{2}}{12 \vdots 0} \frac{-q l}{2} \frac{-q l^{2}}{12}\right\}^{T} .
$$

Finally, the structural balance equation in the global coordinate system can be obtained by coordinate transformation with equations (15), (16), and (18). The integral stiffness matrix of the elastic foundation beam can be expressed as follows:

$$
\left[\left[K_{B}\right]+\left[K_{S}\right]\right][\delta]=[F],
$$

where $\left[K_{B}\right]$ is the stiffness matrix of foundation beam in the global coordinate system; $\left[K_{S}\right]$ is the spring stiffness matrix in the global coordinate system; $[\delta]$ is the node displacement matrix in the global coordinate system; and $[F]$ is the node load array in the global coordinate system. It can be seen that the stiffness matrix of the beam element is only related to the physical properties $\left(E_{w}, E_{\mathrm{cw}}\right)$ and geometric dimensions $(A, I, l, d)$. Therefore, the displacement can be calculated for a specific underground structure when the external load is known.

\section{Case Verification}

3.1. Case Study No. 1. Figure 7(a) shows a top view of the geometric parameters of cross walls and the layout of the wall deformation monitoring points [18]. The bottom of the excavation was divided into three bays by two $0.7 \mathrm{~m}$ thick cross walls. Figure 7(b) shows the excavation conditions and the longitudinal position of supports and cross walls. Within the depth of the excavation, there was mainly alternating silt (SM) and silty clay layers (CL), and the physical parameters of the soil layer are also given in the figure. The cross wall between GL+0 and GL-13.5 m (GL refers to the ground surface level) was filled with miscellaneous fill and poured with concrete as the diaphragm wall under the excavation surface.

According to the finite element calculation principle in the above section, the diaphragm wall between two cross walls was discretized into a finite number of units with length of $1 \mathrm{~m} \times 1 \mathrm{~m}$, of which GL-13 $\mathrm{m} \sim \mathrm{GL}-20 \mathrm{~m}$ were the areas that need to be corrected for stiffness, as shown in Figure 8 . The stiffness values before and after the correction of each element are shown in Tables 1 and 2 .

After the earth pressure outside the pit at different heights was determined, the deformation of each element can be obtained according to the value of element stiffness in Table 2. Figure 9(a) shows the vertical section deformation of the diaphragm wall at SID-1 under different calculation methods at Step5, including the modified Winkler foundation beam (MEFB) method, Winkler foundation beam (EFB) method, and the $3 \mathrm{D}$ analysis results. For comparison, the field observations of Hsieh (2013) are also shown in the figure. As shown, the deformations using the MEFB method were in line with the $3 \mathrm{D}$ analysis results and field observations but were much smaller than the results of the EFB method. It can be seen from the result that there was an error of about $5 \mathrm{~mm}$ between the MEFB method and observation value within the height of 0 to $15 \mathrm{~m}$. This is because in the actual excavation, the previous excavation step has a slight effect on the wall deflection of the next excavation step, which can not be considered by the proposed model.

Figure 9 (b) plots the maximum deformation $\left(\delta_{d, m}\right)$ at different sections in bay 2 . To verify, monitoring points in other bays at the same $d / L$ were also displayed in the figure. As shown, $\delta_{d, m}$ at different sections was close to the $3 \mathrm{D}$ analysis and field observations but much less than that 

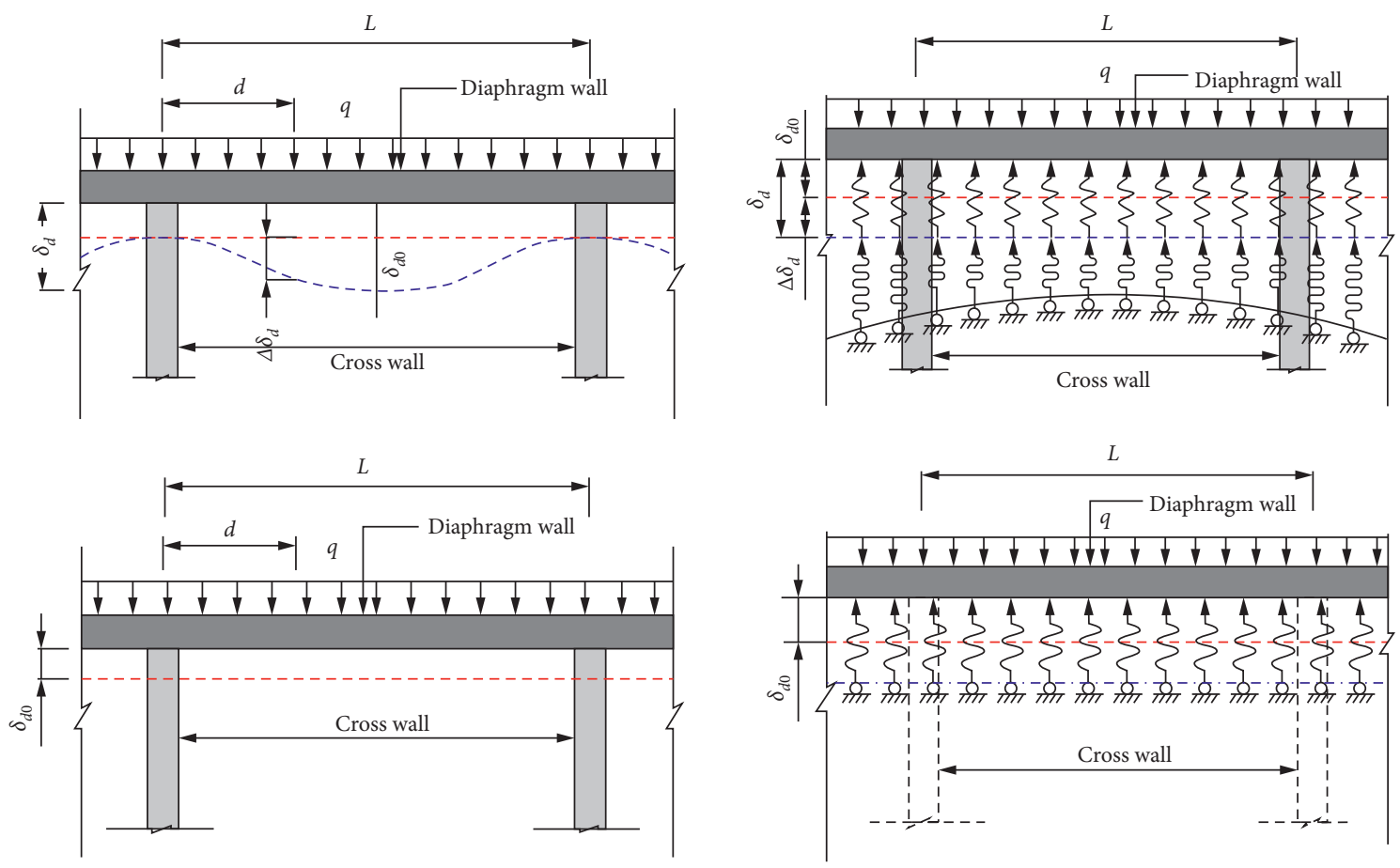

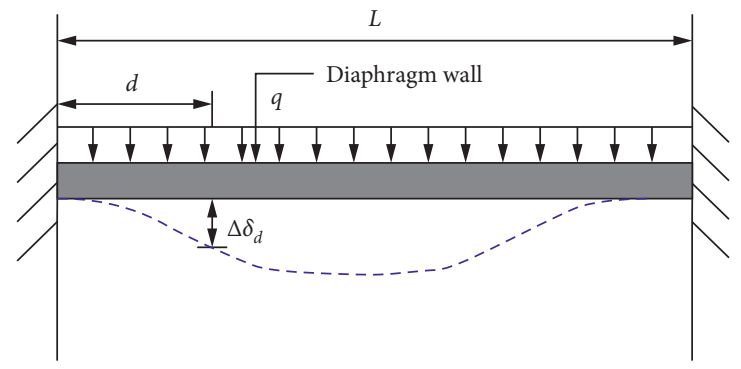

(a)

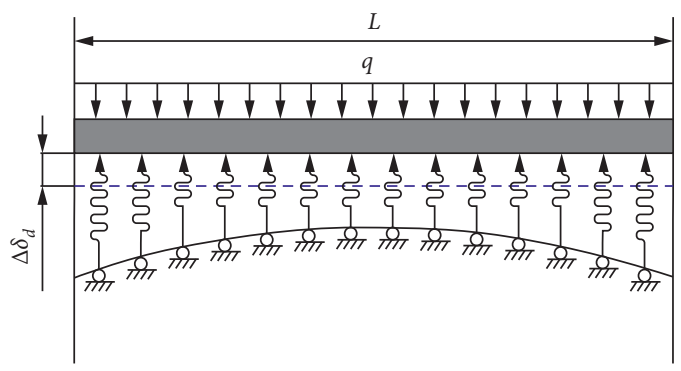

(b)

Figure 4: Derivation of the MEFB method. (a) Deformation mechanism and equivalent stiffness of the diaphragm-cross wall system. (b) Deformation mechanism and equivalent stiffness of the simply supported beam. (c) Deformation mechanism and equivalent stiffness of a fixed beam.

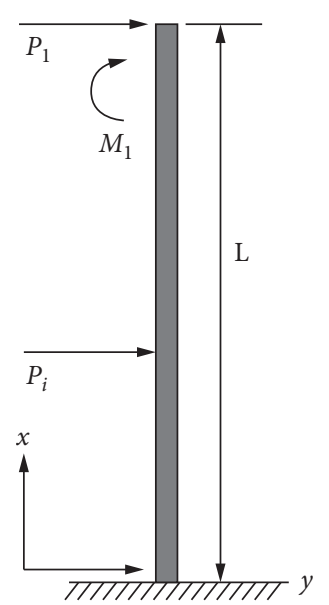

(a)

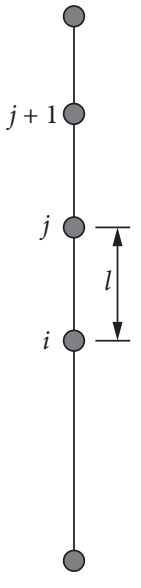

(b)

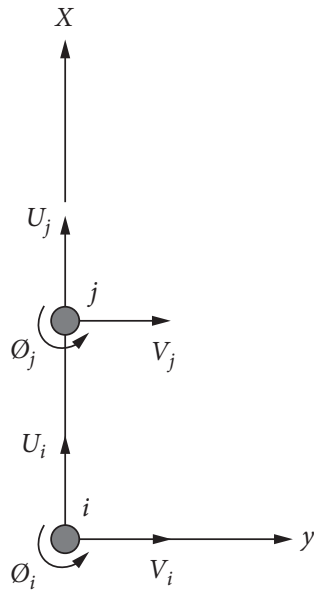

(c)

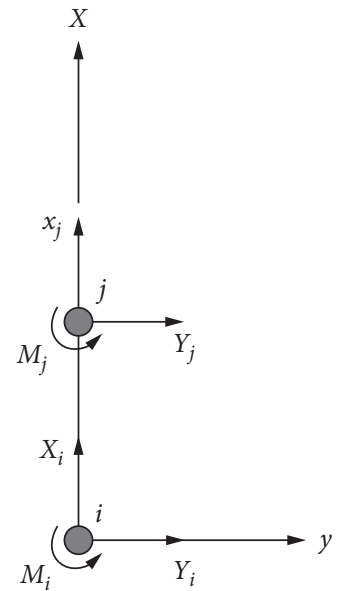

(d)

FIgURE 5: Finite element discretization. 


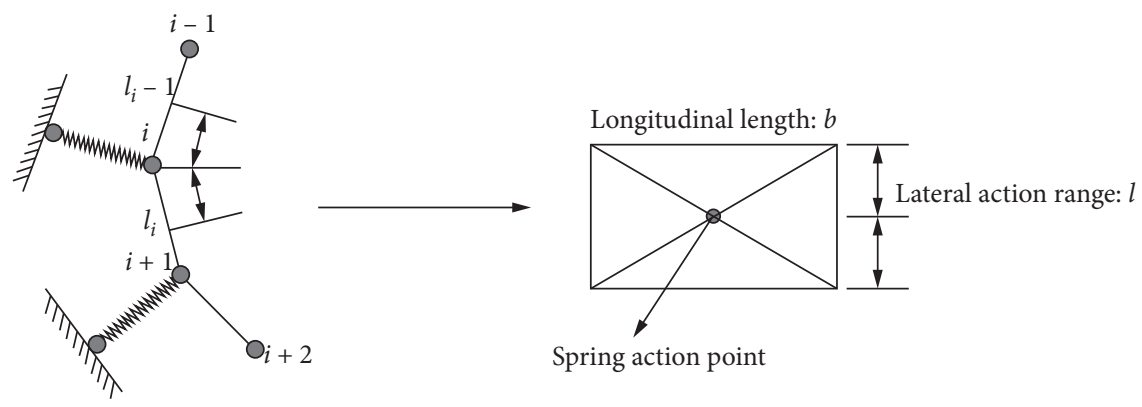

FIgURE 6: Support range of spring element in local coordinate system.

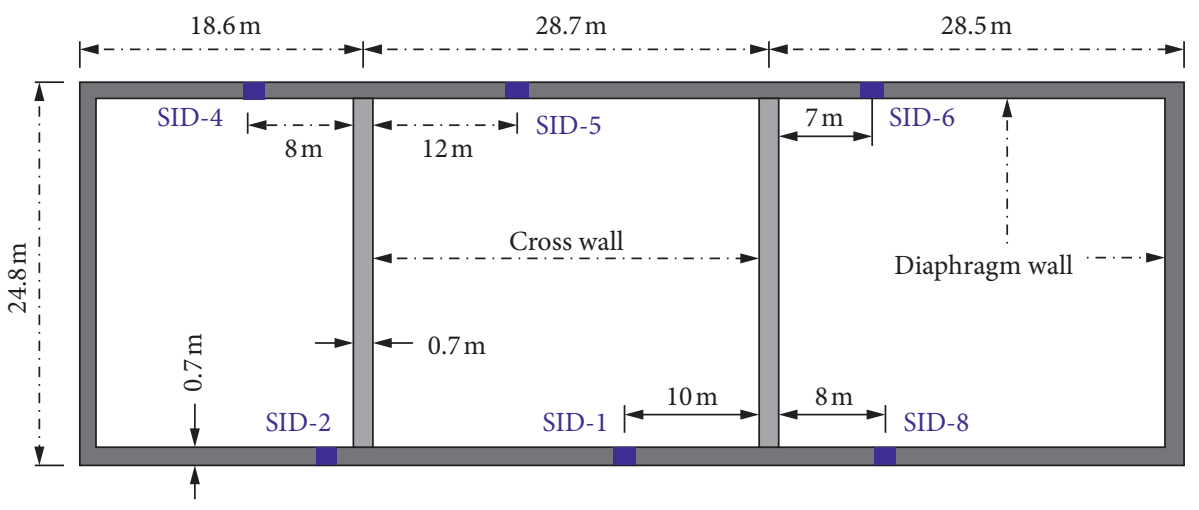

Inclinometer

(a)

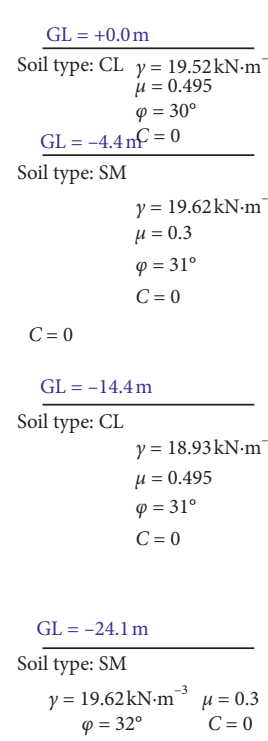

-. . Cross wall dismantled

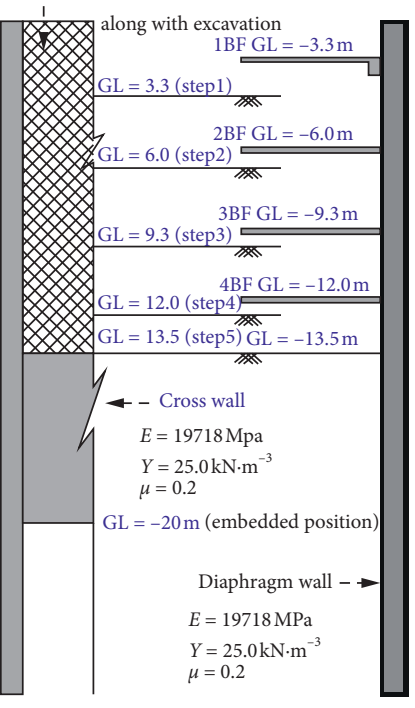

(b)

Figure 7: Excavation geometry and stratigraphy. (a) Cross wall geometry and monitoring layout. (b) Excavation and subsurface soil profiles.

calculated by the EFB method. The support effect of cross walls decreases with the increase of $d$ from calculation sections to the cross wall, reaching the maximum value at section $d / L=0.5$. The $\delta_{d, m}$ at the section $d / L=0$ was equal to $16.43 \mathrm{~mm}$ and $27.73 \mathrm{~mm}$, respectively. The reduction of the diaphragm wall deflection was approximately $40 \%$.
Meanwhile, $\delta_{d, m}$ calculated by the MEFB method was $48.4 \%$ less than that calculated by the EFB method $(53.8 \mathrm{~mm})$. Although $\delta_{d, m}$ calculated by the MEFB method $(27.73 \mathrm{~mm})$ was less than the maximum field observation $(30.42 \mathrm{~mm})$ and the maximum $3 \mathrm{D}$ analysis result $(30.66 \mathrm{~mm})$, the maximum error was within the allowable range of 
engineering calculation compared with $\delta_{d, m}$ of the EFB method $(53.8 \mathrm{~mm})$.

3.2. Case Study No. 2. The geometric layout of the cross wall, buttress wall, and the inclinometer points is shown in Figure 10(a). Three $1 \mathrm{~m}$-thick cross walls divided the excavation into 4 bays, and 12 inclinometer points were, respectively, arranged at cross walls. Figure 10(b) shows the sectional view of each excavation step, soil parameter, and the retaining system. A $1.5 \mathrm{~m}$-thick $57.5 \mathrm{~m}$-deep diaphragm wall was established as enclosure walls of the excavation. The cross wall was backfilled with the miscellaneous soil above the bottom. Seven struts were cast following each stage [19].

The diaphragm wall between two cross walls was discretized into a finite number of units with length of $1 \mathrm{~m} \times 1 \mathrm{~m}$, of which GL-32 $\mathrm{m} \sim$ GL- $45 \mathrm{~m}$ were the areas that need to be corrected for stiffness, as shown in Figure 11. The stiffness values before and after the correction of each element are shown in Tables 3 and 4.

Figure 12(a) shows the deformation of inclination point SO1 under different calculation methods at Step5. For comparison, the field observations from Ou were also listed. As shown in the figure, the predicted wall deflections using the MEFB method were similar to the $3 \mathrm{D}$ analysis results and field observations, but much smaller than the results calculated by the EFB method. The values of the MEFB method were slightly smaller than measured within the height of 0 to $30 \mathrm{~m}$ due to the same reason as Case1.

$\delta_{d, m}$ at different sections using different methods in bay 2 is shown in Figure 12(b). For comparison, inclinometer points in other bays at the same $d / L$ were also displayed in the figures. The results of the MEFB method were close to the $3 \mathrm{D}$ analysis and field observations but were much less than those of the EFB method. The restraining effect was also the largest at the section $d / L=0$ where cross walls were installed and decreased to the midline of the bays. $\delta_{\mathrm{d} m}$ at the section $d / L=0$ was calculated to have a $23.8 \%$ reduction compared with the value at the section $d / L=0.5$. Owing to the support function of the cross wall, $\delta_{d, m}$ calculated by the MEFB method was $59.4 \%$ less than that calculated by the EFB method $(108.6 \mathrm{~mm})$. Similar to Case1, the maximum error of the MEFB method was within the allowable range of engineering calculation. Besides, the calculated value at SI2 was less than the measured value because the equipment stayed permanently according to the construction record.

\section{Engineering Design and Application}

4.1. Project Overview. The proposed method in this paper had been applied to a completed excavation project of Yongdingmen station of Beijing Metro Line 8, abbreviated as the YDM project. Monitoring points and wall excavation geometry are shown in Figure 13(a). A diaphragm wall with $1.2 \mathrm{~m}$ thickness was used as the retaining system of the excavation. Several $1 \mathrm{~m}$-thick cross walls were used to divide the excavation into 16 bays, and 12 inclinometers at different locations were installed on the walls. Figure 13(b) shows the schematic graph of retaining structure, stratum, and excavation (section A-A). The cross wall was backfilled within concrete between GL-32 $\mathrm{m}$ and GL- $44 \mathrm{~m}$. The beamfloor was densely arranged at intervals of several meters in the horizontal direction. The interval of $1 \mathrm{BF}, 2 \mathrm{BF}$, and $3 \mathrm{BF}$ were $4.5 \mathrm{~m}, 9 \mathrm{~m}$, and $9 \mathrm{~m}$, respectively. In addition, a $4 \mathrm{~m}$ thickness concrete slab was performed at the bottom of the foundation pit. The construction depth was $36.5 \mathrm{~m}$, and the groundwater level was GL-19.0 m. The toes of diaphragm walls and cross walls were embedded $8 \mathrm{~m}$ in the $\mathrm{Cb}$ layer.

Figure 14 illustrates the YDM project excavation and threedimensional finite element mesh used for analysis. A 10-noded tetrahedral element was applied to simulate the soil volume. Soil movements normal to the four vertical sides were restrained (roller boundary), whereas soil movements were restrained in all directions at the bottom of the geometry (fixed boundary). The distance between the diaphragm walls and the outer boundary of the mesh was larger than five times the final excavation depth $(\mathrm{He})$ to minimize the boundary effect [20].

The Hardening Soil model [16], abbreviated as HS model, was adopted for this numerical model. This model must input 11 parameters $\left(c l, \varnothing, l \psi, E_{50}^{\text {ref }}, E_{\text {oed }}^{\text {ref }}, E_{\text {ur }}^{\text {ref }}\right.$, $\left.m, v_{\mathrm{ur}}, p^{\mathrm{ref}}, K_{o}^{\mathrm{NC}}, R_{f}\right)$ to reflect the mechanical behavior of soil. The structural members such as diaphragm walls, cross walls, and concrete slabs employed were made of plate elements and simulated as linear elastic material as well as the concrete strut. Considering the possibility of the microcracks in concrete after structural deflection, the elastic modulus of the structure has been reduced by $20 \%$ [21, 22]. The input parameters of the soil layer and structure are all shown in Table 5.

4.2. Results and Discussion. Figure 15(a) shows the measured deformation at ZQT-6 at Step6 and those calculated using different methods. Different from the two cases mentioned in the previous study, the cross wall was only constructed from GL-32 m to GL- $44 \mathrm{~m}$. Therefore, there was no significant difference between the MEFB method and the EFB method for the wall deflection above the bottom of the foundation pit. Within the height of 0 to $-19 \mathrm{~m}$, the deformation calculated by the MEFB method was a bit smaller than the field observation. However, due to the water level recharge to GL-19m in step 5, the field observations were smaller than the results of the MEFB method. Under this complex excavation condition, the proposed results did not fully match the field observation and $3 \mathrm{D}$ analysis, but the results were still within a reasonable range compared with the EFB method.

Figure 15(b) shows that $\delta_{d, m}$ at different sections was fitting well with the $3 \mathrm{D}$ analysis results and field observations but was much less than the result of the EFB method. The support effect of the cross wall decreases with the increase of distance $d$ from calculation sections to the cross wall, reaching the maximum value at section $d / L=0.5$. The $\delta_{d, m}$ value at section $d / L=0$ was calculated to have a $16.3 \%$ reduction compared with section $d / L=0.5$. This reduction ratio was smaller than that of Case 1 and Case 2 due to the smaller cross wall interval $(L)$ which affected stiffness. Besides, $\delta_{d, m}$ calculated by the 


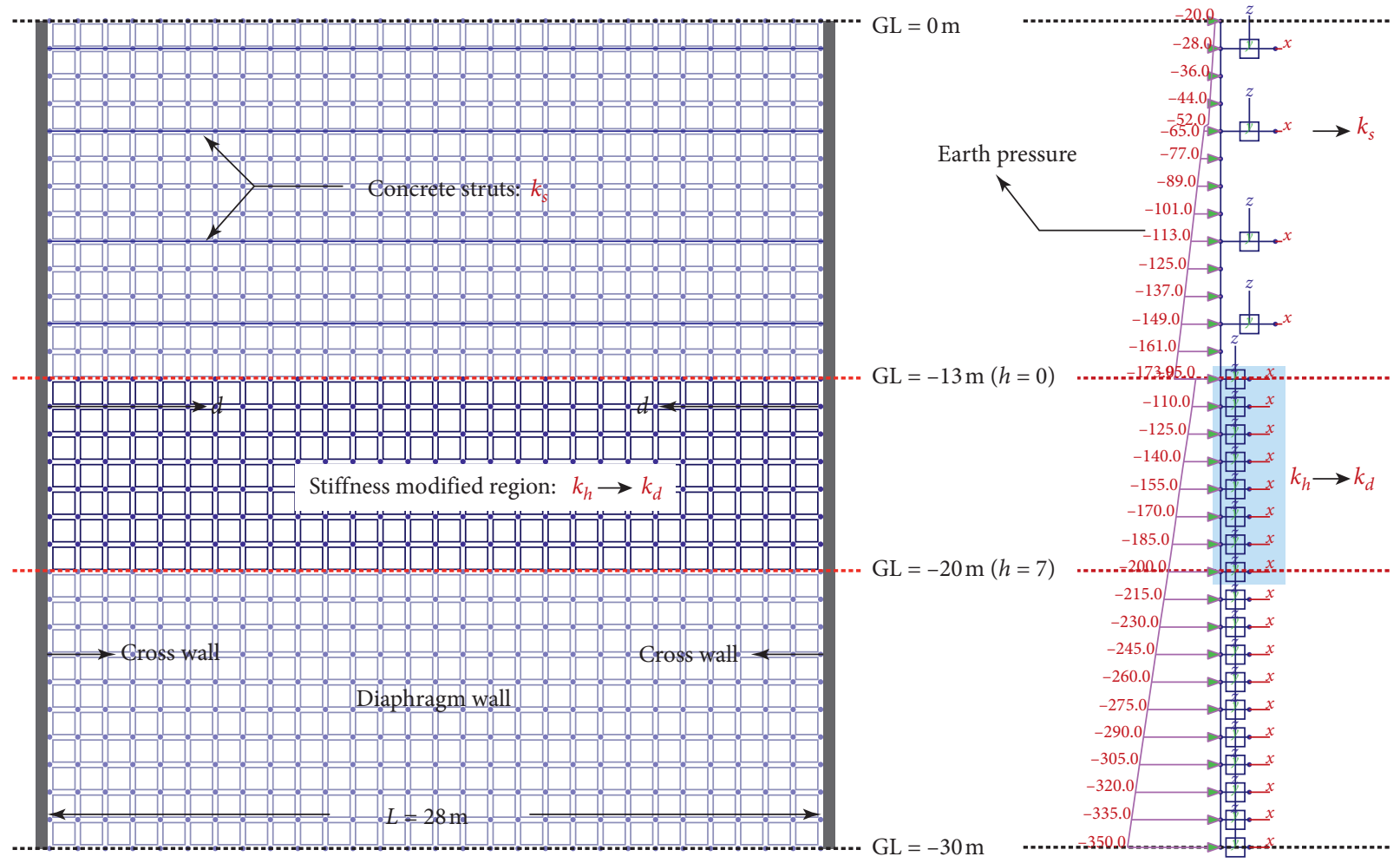

Figure 8: Schematic diagram of element discretization and stiffness modified area.

TABLe 1: The stiffness of foundation spring calculated by equation (3).

\begin{tabular}{|c|c|c|c|c|c|c|c|c|c|c|c|c|c|c|}
\hline$k_{h}$ & $d=1$ & $d=2$ & $d=3$ & $d=4$ & $d=5$ & $d=6$ & $d=7$ & $d=8$ & $d=9$ & $d=10$ & $d=11$ & $d=12$ & $d=13$ & $d=14$ \\
\hline$h=1$ & 10 & 10 & 10 & 10 & 10 & 10 & 10 & 10 & 10 & 10 & 10 & 10 & 10 & 10 \\
\hline$h=2$ & 20 & 20 & 20 & 20 & 20 & 20 & 20 & 20 & 20 & 20 & 20 & 20 & 20 & 20 \\
\hline$h=3$ & 30 & 30 & 30 & 30 & 30 & 30 & 30 & 30 & 30 & 30 & 30 & 30 & 30 & 30 \\
\hline$h=4$ & 40 & 40 & 40 & 40 & 40 & 40 & 40 & 40 & 40 & 40 & 40 & 40 & 40 & 40 \\
\hline$h=5$ & 50 & 50 & 50 & 50 & 50 & 50 & 50 & 50 & 50 & 50 & 50 & 50 & 50 & 50 \\
\hline$h=6$ & 60 & 60 & 60 & 60 & 60 & 60 & 60 & 60 & 60 & 60 & 60 & 60 & 60 & 60 \\
\hline$h=7$ & 70 & 70 & 70 & 70 & 70 & 70 & 70 & 70 & 70 & 70 & 70 & 70 & 70 & 70 \\
\hline
\end{tabular}

TABLE 2: The stiffness of foundation spring calculated by equation (9).

\begin{tabular}{|c|c|c|c|c|c|c|c|c|c|c|c|c|c|c|}
\hline$k_{h}$ & $d=1$ & $d=2$ & $d=3$ & $d=4$ & $d=5$ & $d=6$ & $d=7$ & $d=8$ & $d=9$ & $d=10$ & $d=11$ & $d=12$ & $d=13$ & $d=14$ \\
\hline$h=1$ & 877 & 231 & 109 & 66 & 46 & 35 & 28 & 24 & 21 & 19 & 18 & 16 & 15 & 15 \\
\hline$h=2$ & 1755 & 462 & 218 & 132 & 92 & 70 & 57 & 48 & 42 & 38 & 35 & 33 & 31 & 29 \\
\hline$h=3$ & 2632 & 693 & 327 & 197 & 137 & 105 & 85 & 72 & 63 & 57 & 53 & 49 & 46 & 44 \\
\hline$h=4$ & 3510 & 924 & 435 & 263 & 183 & 140 & 113 & 96 & 85 & 76 & 70 & 65 & 62 & 59 \\
\hline$h=5$ & 4387 & 1155 & 544 & 329 & 229 & 175 & 142 & 120 & 106 & 95 & 88 & 82 & 77 & 73 \\
\hline$h=6$ & 5265 & 1387 & 653 & 395 & 275 & 210 & 170 & 145 & 127 & 114 & 105 & 98 & 92 & 88 \\
\hline$h=7$ & 6144 & 1620 & 763 & 462 & 322 & 246 & 199 & 171 & 149 & 134 & 123 & 115 & 108 & 104 \\
\hline
\end{tabular}

MEFB method was less than that of the EFB method by over $38.8 \%$. This reduction rate was significantly smaller than that of Case 1 and Case 2 because the cross wall only existed below the pit bottom. The inclinometer points ZQT10 and ZQT11 were located at a structural hinge with a strong corner effect, so the measured value was much smaller.
Figure 16 shows the results of the middle section of the diaphragm wall in step 6 under the two methods, where (a) denotes the earth pressure outside the diaphragm wall, (b), $(\mathrm{c})$, and $(\mathrm{d})$ denote the wall deflection $\left(\delta_{d}\right)$, bending moment $\left(M_{v}\right)$, and shear force $\left(F_{s}\right)$, respectively. Table 6 shows the maximum values in two calculation cases. 


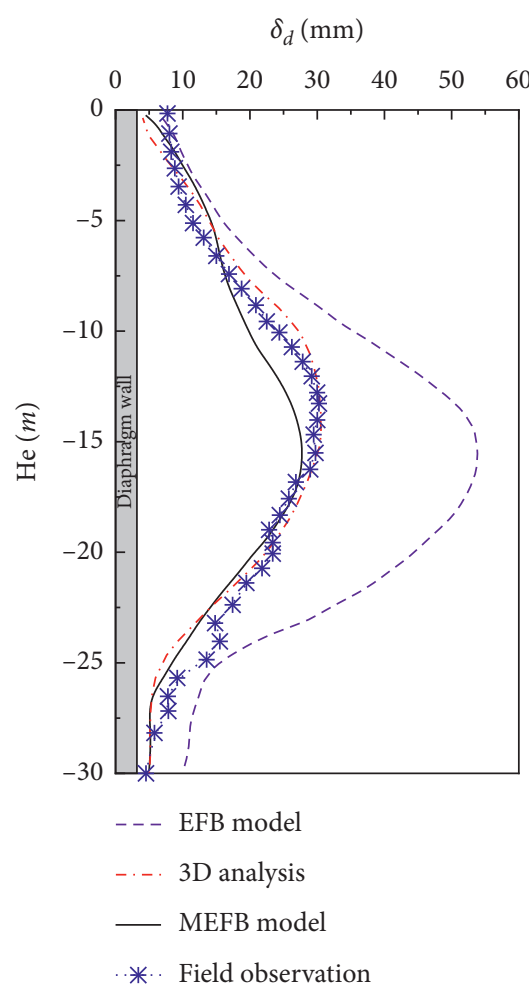

(a)

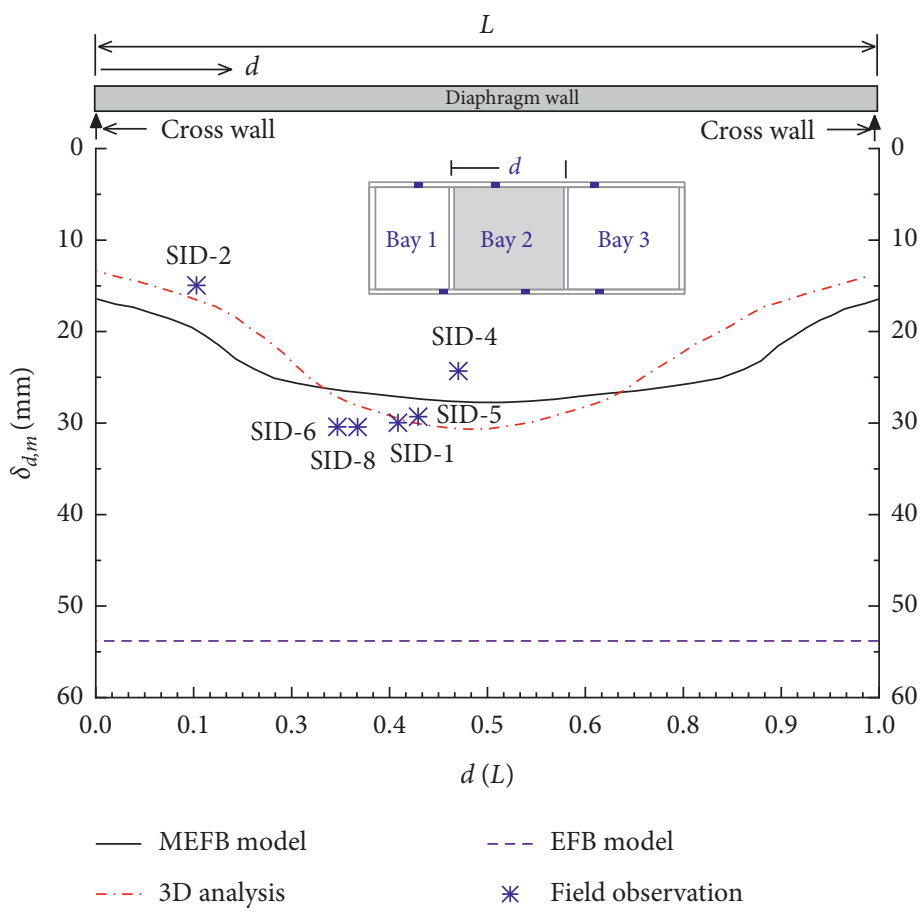

(b)

FIGURE 9: Comparison of the computed maximum lateral wall deflections at various sections and those from field observation for case 1. (a) Wall deformation at SID-1. (b) Wall deformations at GL-15.0 m in various cross-sections (d/L).
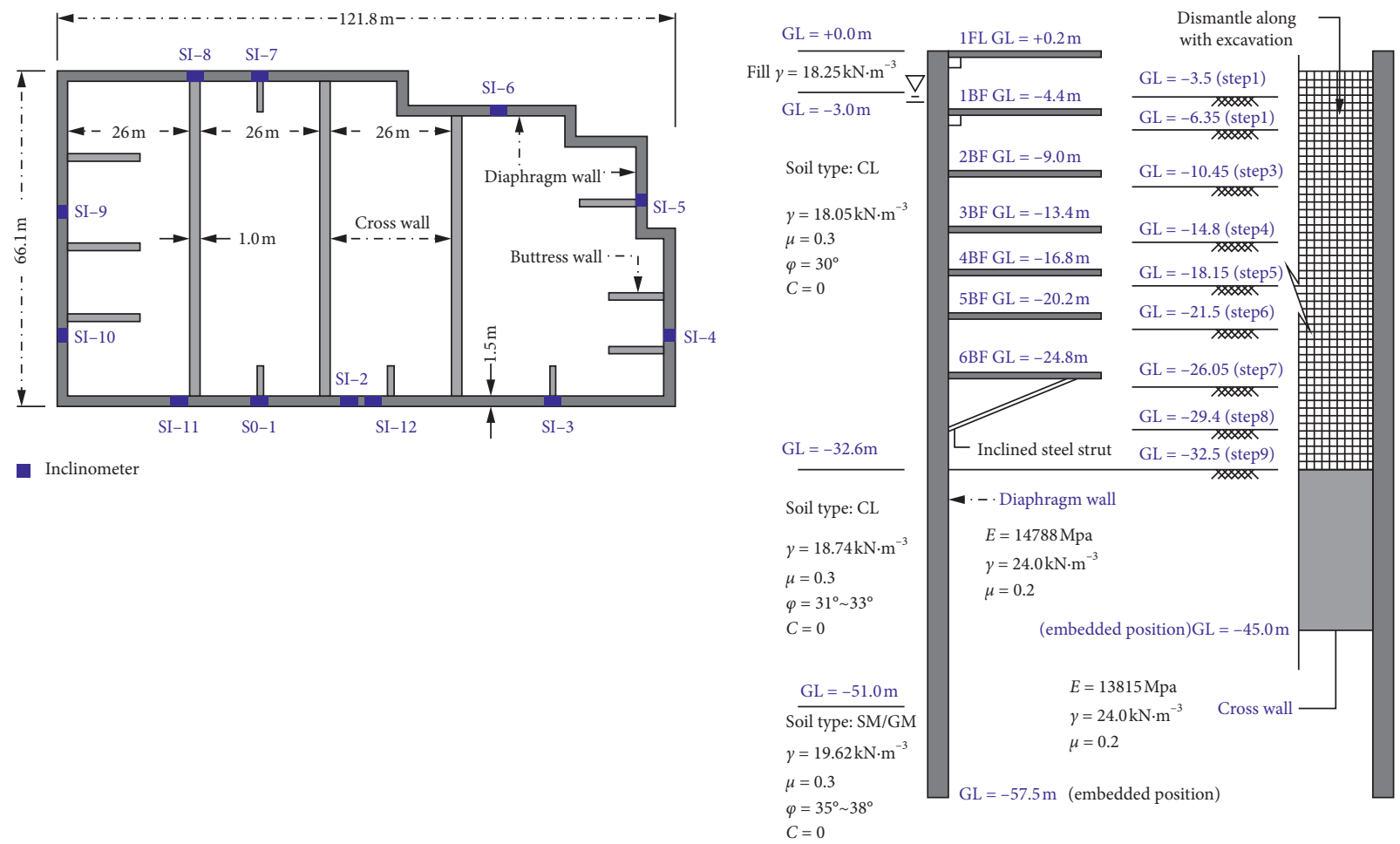

(a)

(b)

FIgURE 10: Excavation geometry and stratigraphy. (a) Cross wall geometry and monitoring layout. (b) Excavation and subsurface soil profiles. 


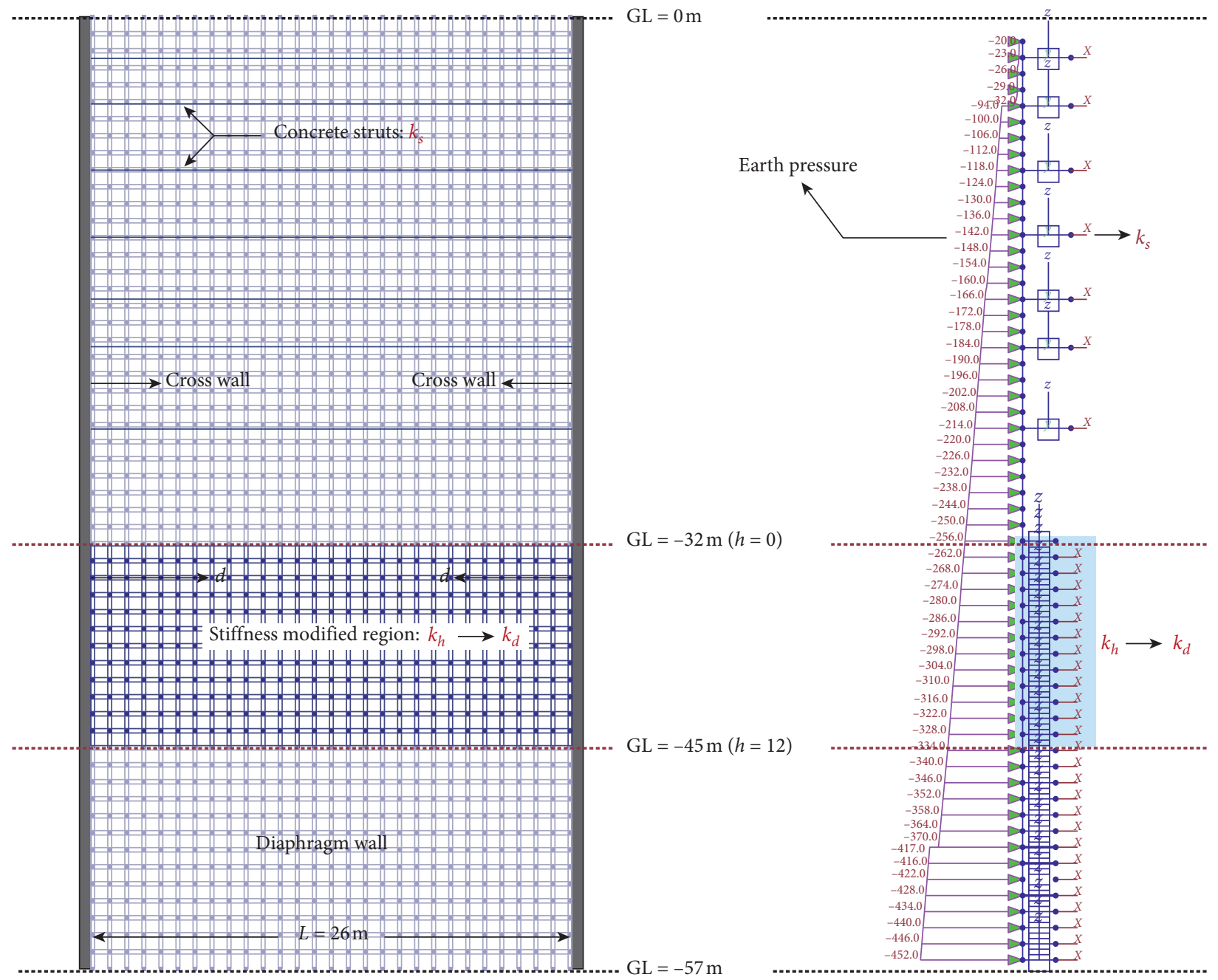

Figure 11: Schematic diagram of element discretization and stiffness modified area.

TABLE 3: The stiffness calculated by equation (3).

\begin{tabular}{lccccccccccccc}
\hline$k_{h}$ & $d=1$ & $d=2$ & $d=3$ & $d=4$ & $d=5$ & $d=6$ & $d=7$ & $d=8$ & $d=9$ & $d=10$ & $d=11$ & $d=12$ & $d=13$ \\
\hline$h=1$ & 10 & 10 & 10 & 10 & 10 & 10 & 10 & 10 & 10 & 10 & 10 & 10 \\
$h=2$ & 20 & 20 & 20 & 20 & 20 & 20 & 20 & 20 & 20 & 20 & 20 & 20 & 20 \\
$h=3$ & 30 & 30 & 30 & 30 & 30 & 30 & 30 & 30 & 30 & 30 & 30 & 30 & 30 \\
$h=4$ & 40 & 40 & 40 & 40 & 40 & 40 & 40 & 40 & 40 & 40 & 40 & 40 & 40 \\
$h=5$ & 50 & 50 & 50 & 50 & 50 & 50 & 50 & 50 & 50 & 50 & 50 & 50 & 50 \\
$h=6$ & 60 & 60 & 60 & 60 & 60 & 60 & 60 & 60 & 60 & 60 & 60 & 60 & 60 \\
$h=7$ & 70 & 70 & 70 & 70 & 70 & 70 & 70 & 70 & 70 & 70 & 70 & 70 & 70 \\
$h=8$ & 80 & 80 & 80 & 80 & 80 & 80 & 80 & 80 & 80 & 80 & 80 & 80 & 80 \\
$h=9$ & 90 & 90 & 90 & 90 & 90 & 90 & 90 & 90 & 90 & 90 & 90 & 90 & 90 \\
$h=10$ & 100 & 100 & 100 & 100 & 100 & 100 & 100 & 100 & 100 & 100 & 100 & 100 & 100 \\
$h=11$ & 110 & 110 & 110 & 110 & 110 & 110 & 110 & 110 & 110 & 110 & 110 & 110 & 110 \\
$h=12$ & 120 & 120 & 120 & 120 & 120 & 120 & 120 & 120 & 120 & 120 & 120 & 120 & 120 \\
\hline
\end{tabular}

The results were similar in the upper part of the wall but were much smaller after excavation to a certain depth with the MEFB method. The values of $\delta_{d, m}, M_{V, m}$, and $F_{S, m}$ were reduced by $38.1 \%, 14.8 \%$, and $25.3 \%$, respectively. Besides, the wall reinforcement area $A_{S}$ calculated based on the maximum bending moment can be reduced by $16.5 \%$ compared with the EFB method. Therefore, the MEFB method can be used for the structural calculation to achieve the most economical design within the limit bearing capacity.

\section{Parametric Study of the Cross Wall}

The MEFB method was expected to optimize the design parameters of the cross wall. Ou et al. [23] proposed the plane 
TABLE 4: The stiffness calculated by equation (9).

\begin{tabular}{lccccccccccccc}
\hline$k_{h}$ & $d=1$ & $d=2$ & $d=3$ & $d=4$ & $d=5$ & $d=6$ & $d=7$ & $d=8$ & $d=9$ & $d=10$ & $d=11$ & $d=12$ & $d=13$ \\
\hline$h=1$ & 1600 & 452 & 211 & 124 & 84 & 61 & 48 & 39 & 33 & 29 & 25 & 23 \\
$h=2$ & 3200 & 904 & 422 & 248 & 167 & 123 & 96 & 78 & 66 & 57 & 51 & 46 & 42 \\
$h=3$ & 4799 & 1356 & 633 & 373 & 251 & 184 & 143 & 117 & 99 & 86 & 76 & 69 & 63 \\
$h=4$ & 6399 & 1808 & 844 & 497 & 334 & 245 & 191 & 156 & 132 & 115 & 102 & 92 & 84 \\
$h=5$ & 7999 & 2260 & 1055 & 621 & 418 & 306 & 239 & 195 & 165 & 143 & 127 & 115 & 106 \\
$h=6$ & 9599 & 2711 & 1266 & 745 & 501 & 368 & 287 & 234 & 198 & 172 & 153 & 138 & 127 \\
$h=7$ & 1198 & 3163 & 1477 & 870 & 585 & 429 & 335 & 273 & 231 & 201 & 178 & 161 \\
$h=8$ & 12798 & 3615 & 1688 & 994 & 668 & 490 & 383 & 312 & 264 & 229 & 204 & 184 & 148 \\
$h=9$ & 14398 & 4067 & 1899 & 1118 & 752 & 552 & 430 & 351 & 297 & 258 & 229 & 207 & 190 \\
$h=10$ & 15998 & 4519 & 2110 & 1242 & 835 & 613 & 478 & 390 & 330 & 287 & 255 & 230 & 211 \\
$h=11$ & 17597 & 4971 & 2321 & 1366 & 919 & 674 & 526 & 430 & 363 & 316 & 280 & 253 & 232 \\
$h=12$ & 19197 & 5423 & 2532 & 1491 & 1003 & 736 & 574 & 469 & 396 & 344 & 306 & 276 & 253 \\
\hline
\end{tabular}

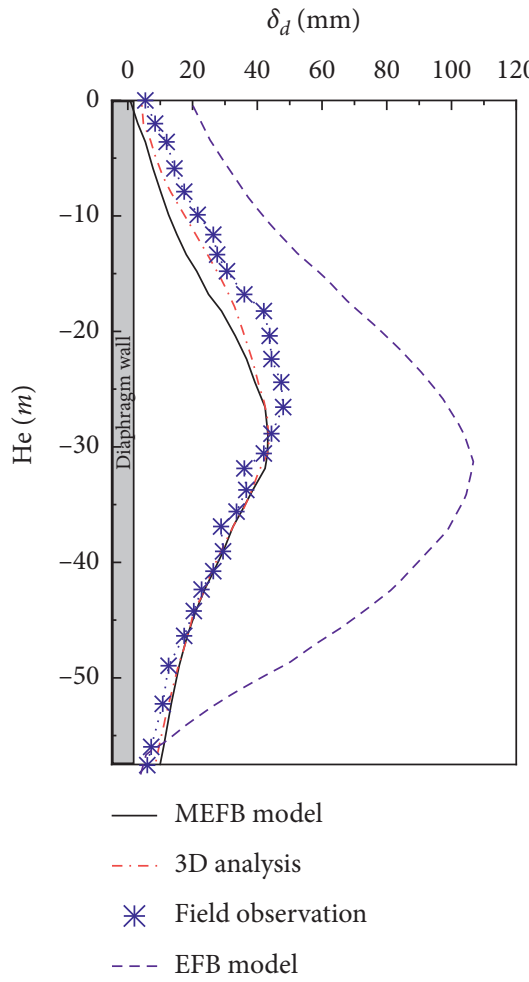

(a)

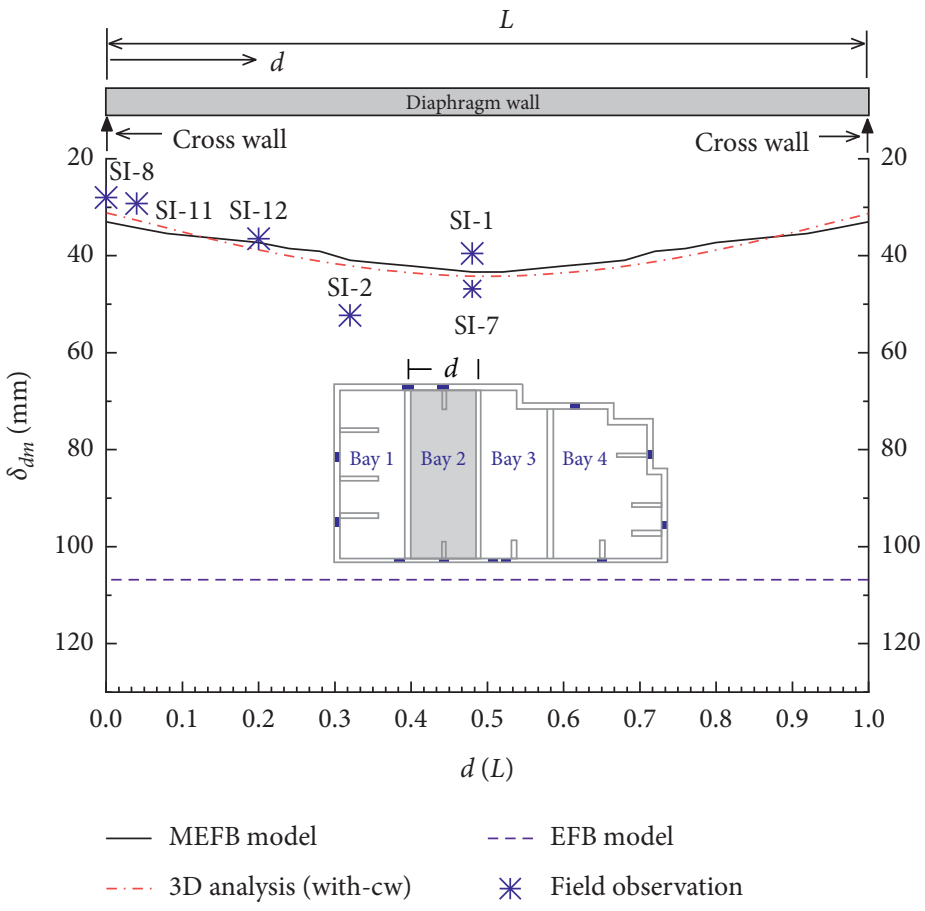

(b)

FIGURE 12: Comparison of the computed maximum lateral wall deflections at various sections and those from field observation for case 2. (a) Wall deformation at SI-8. (b) Wall deformations at GL-30.0m in various cross-sections $(\mathrm{d} / \mathrm{L})$.

strain ratio (PSR) which was initially defined as the ratio of the maximum deformation of each profile and the maximum deformation under the plane strain state. Based on the definition of $\mathrm{Ou}$, this paper defined the $\mathrm{PSR}_{d}$ as

$$
\operatorname{PSR}_{d}=\frac{\Delta \delta_{d, \mathrm{me}}}{\delta_{h, \mathrm{ef}}}
$$

where $\Delta \delta_{d \text { me }}$ is the maximum wall deformation on various sections of the MEFB method and $\delta_{h, p s}$ is the maximum wall deformation under the EFB method. A smaller $\mathrm{PSR}_{d}$ value represents a stronger supporting function of the cross wall and vice versa. When $\mathrm{PSR}_{d}=1$, it means that there was no cross wall effect.
5.1. Effect of the Cross Wall Interval. The cross wall interval was a determining parameter for calculating the equivalent stiffness. Therefore, variations of $\mathrm{PSR}_{d}$ values at different sections $(d / L)$ under the case of $B / L=\infty, 2,4,6,8,16,20$ are shown in Figure 17. Of these, $B / L=\infty$ meant no cross wall. In other cases, the corner effect causes a notably small $\mathrm{PSR}_{d}$ value at the section $d / L=0$ and $d / L=1$ and reached the maximum values at the section of $d / L=0.5$. Besides, the $\mathrm{PSR}_{d}$ value of each section reduced with the decrease of the interval. When the interval decreased to $B / L=8$, the $\mathrm{PSR}_{d}$ values near the cross wall decreased significantly and the curve becomes smooth. For $B / L=16$ and 20, the $\mathrm{PSR}_{d}$ curve remained subdued and the reduction of $\mathrm{PSR}_{d}$ values was limited. 


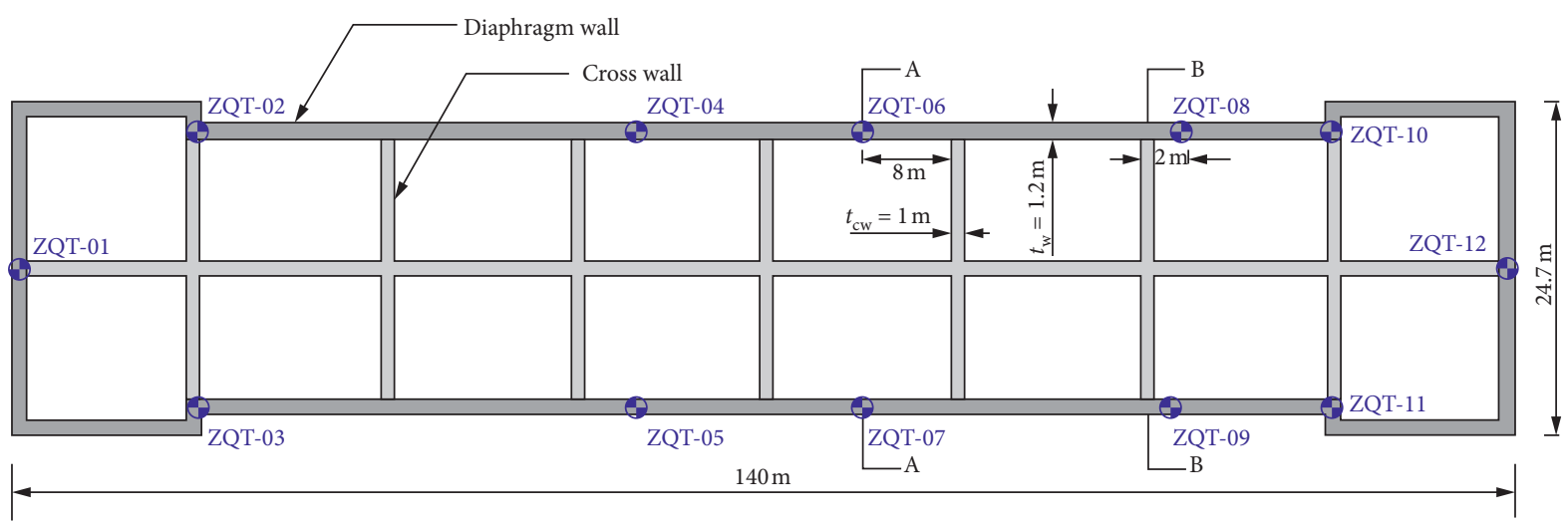

Inclinometer

(a)
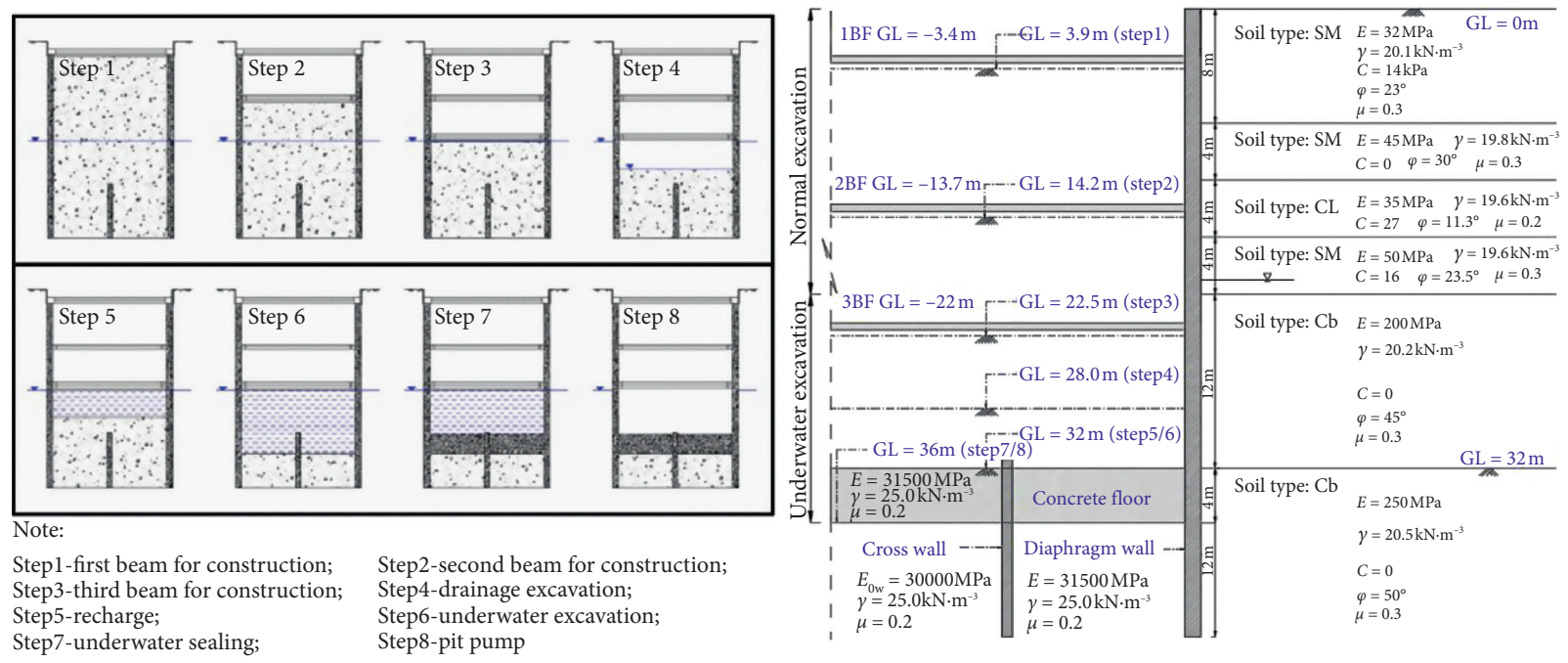

(b)

FIGURE 13: Excavation geometry and stratigraphy for YDM project. (a) Cross wall geometry and monitoring layout. (b) Excavation sequence and soil layer profiles.
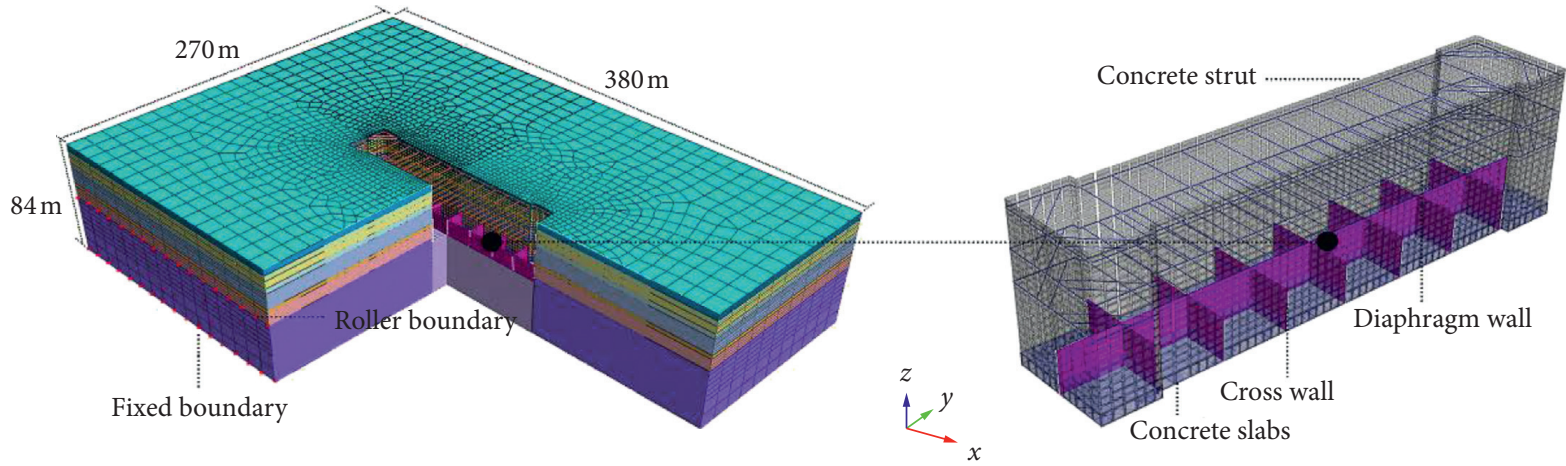

Figure 14: Three-dimensional finite element mesh for analysis.

In conclusion, the reduction of $\mathrm{PSR}_{d}$ was limited when the interval was reduced to a certain extent. Too much reduction of the cross wall interval did not make full use of the corner effect. Therefore, each project has a critical width ratio $\left(B / L_{\mathrm{cr}}\right)$. The $\left(B / L_{\mathrm{cr}}\right)$ of YDM project was 8 , and it meant that that the excavation was best divided into 8 bays. 
TABLE 5: Input parameters of the soil layer and structural members for the YDM excavation.

\begin{tabular}{|c|c|c|c|c|c|c|c|c|c|c|}
\hline Soil & $\mu$ & $c_{s}(\mathrm{kPa})$ & $K_{0}^{\mathrm{NC}}$ & $E_{50}^{\text {ref }}(\mathrm{MPa})$ & $E_{\text {oed }}^{\text {ref }}(\mathrm{MPa})$ & $E_{\mathrm{ur}}^{\mathrm{ref}}(\mathrm{MPa})$ & $R_{f}$ & $m$ & $\varphi\left({ }^{\circ}\right)$ & $\psi\left({ }^{\circ}\right)$ \\
\hline SM & 0.33 & 0 & 0.64 & 18.347 & 18.347 & 55.041 & 0.9 & 0.5 & 21.4 & 0 \\
\hline CL & 0.33 & 23 & 0.84 & 22.439 & 22.439 & 67.317 & 0.9 & 1.0 & 9.3 & 0 \\
\hline SM & 0.3 & 11 & 0.61 & 23.009 & 23.009 & 69.297 & 0.9 & 0.5 & 23.0 & 0 \\
\hline SM & 0.3 & 8 & 0.59 & 31.218 & 31.218 & 63.645 & 0.9 & 1.0 & 24.2 & 0 \\
\hline $\mathrm{CB}$ & 0.27 & 5 & 0.35 & 132 & 132 & 396 & 0.9 & 1.0 & 40.0 & 10 \\
\hline CL & 0.3 & 30 & 0.74 & 32.076 & 32.076 & 96.228 & 0.9 & 0.5 & 15.0 & 0 \\
\hline $\mathrm{CB}$ & 0.26 & 5 & 0.29 & 198 & 198 & 594 & 0.9 & 1.0 & 45.0 & 15 \\
\hline \multicolumn{3}{|c|}{ Structure type } & \multicolumn{2}{|c|}{ Thickness (m) } & \multicolumn{2}{|c|}{$E(\mathrm{MPa})$} & \multicolumn{2}{|c|}{$\gamma\left(\mathrm{kN} \cdot \mathrm{m}^{-3}\right)$} & \multicolumn{2}{|c|}{$\mu$} \\
\hline \multicolumn{3}{|c|}{ Diaphragm wall } & \multicolumn{2}{|c|}{1.2} & \multicolumn{2}{|c|}{$25200^{*}$} & \multicolumn{2}{|c|}{25} & \multicolumn{2}{|c|}{0.15} \\
\hline \multicolumn{3}{|c|}{ Cross wall } & \multicolumn{2}{|c|}{1.0} & \multicolumn{2}{|c|}{$25200^{*}$} & \multicolumn{2}{|c|}{25} & \multicolumn{2}{|c|}{0.15} \\
\hline \multicolumn{3}{|c|}{ Concrete slabs } & \multicolumn{2}{|c|}{4.0} & \multicolumn{2}{|c|}{$23100^{*}$} & \multicolumn{2}{|c|}{24} & \multicolumn{2}{|c|}{0.3} \\
\hline \multicolumn{3}{|c|}{ Concrete strut } & \multicolumn{2}{|c|}{1.0} & \multicolumn{2}{|c|}{$6200^{*}$} & \multicolumn{2}{|c|}{25} & \multicolumn{2}{|c|}{0.15} \\
\hline
\end{tabular}

*Young's modulus was reduced by $20 \%$.

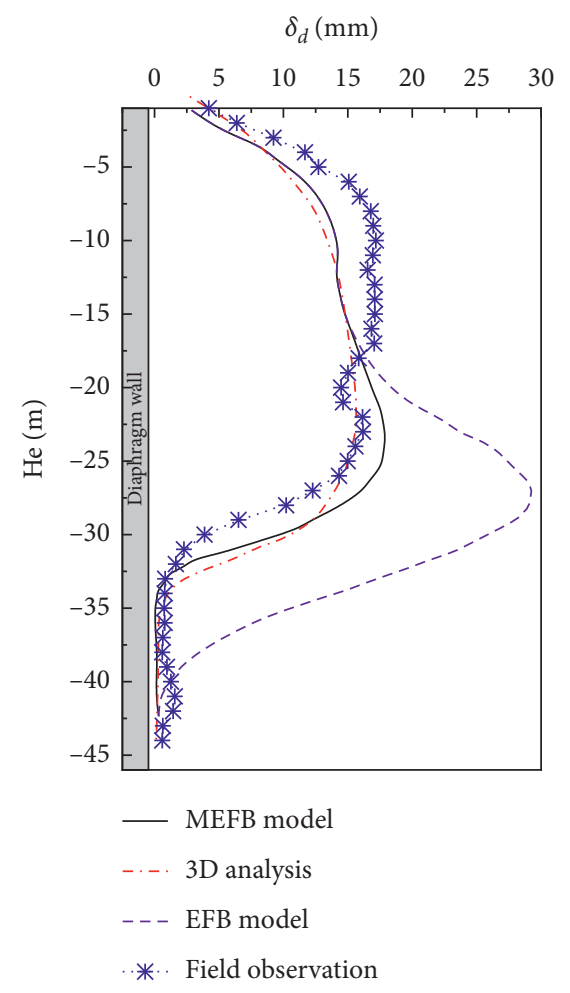

(a)

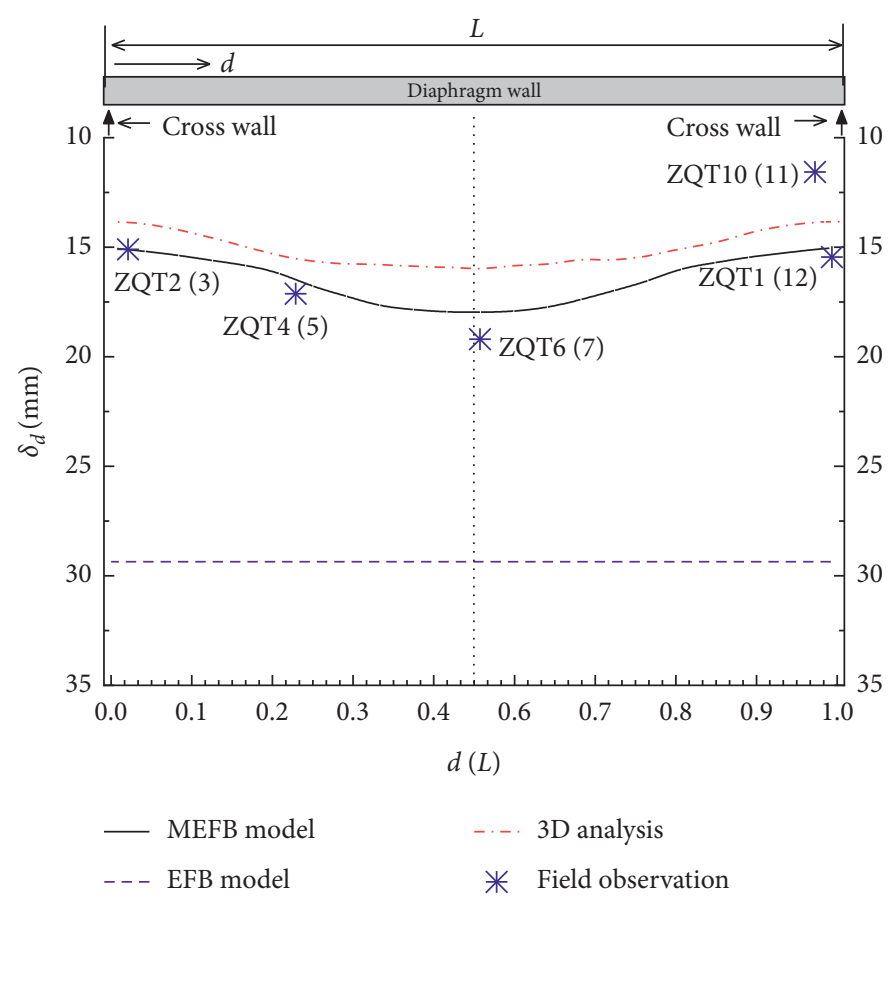

(b)

FIGURE 15: Comparison of the computed maximum lateral wall deflections at various sections and those from field observation for YDM. (a) Wall deflection at ZTQ-6. (b) Wall deformations at GL-26.0m in various cross-sections (d/L).

5.2. Effect of the Cross Wall Depth. According to the stiffness calculation formula, the embedding depth of the cross wall $\left(h_{c w}\right)$ was another parameter that determines the spring stiffness. Theoretically, the $\mathrm{PSR}_{d}$ value was the smallest when $h_{c w} / h_{d w}=1$, but the construction cost was wasted. Therefore, a critical embedded depth ratio, $\left(h_{c w} / h_{d w}\right)_{c r}$, was defined to study the optimal cross wall embedded ratio. Any value beyond this critical ratio will no longer cause the $\mathrm{PSR}_{d}$ value to decrease.
By plotting the relationship between the $\mathrm{PSR}_{d}$ values at section A-A and the ratio of $h_{c w} / h_{d w}$, the critical embedding depth for YDM project can be expressed as $\left(h_{c w} /\right.$ $\left.h_{d w}\right)_{c r}=0.5$, as shown in Figure 18; when $\left(h_{c w} / h_{d w}\right)_{c r}$ was greater than 0.5 , the $\mathrm{PSR}_{d}$ values no longer decreased. This meant that if the other construction factors such as concrete filling were ignored, it was most reasonable to set the cross wall embedded depth as half of the diaphragm wall embedded depth. 


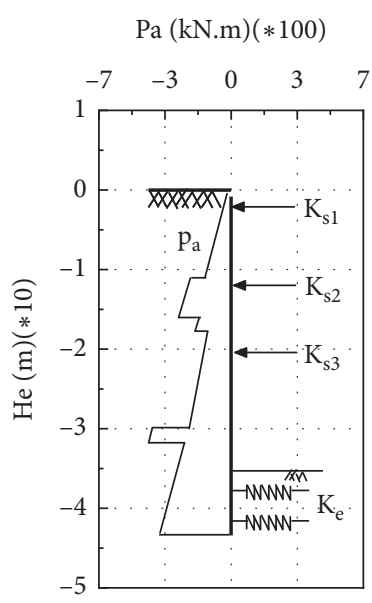

(a)

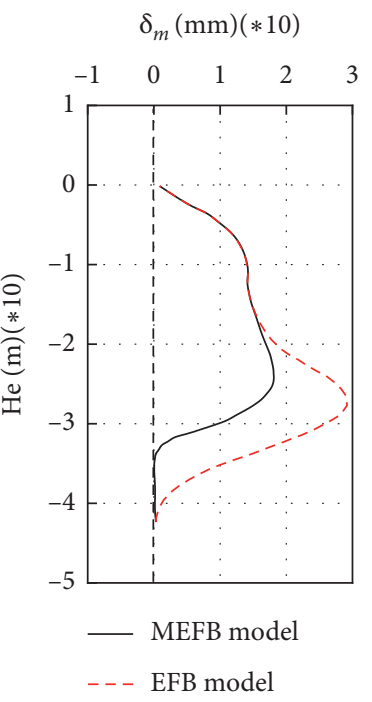

(b)

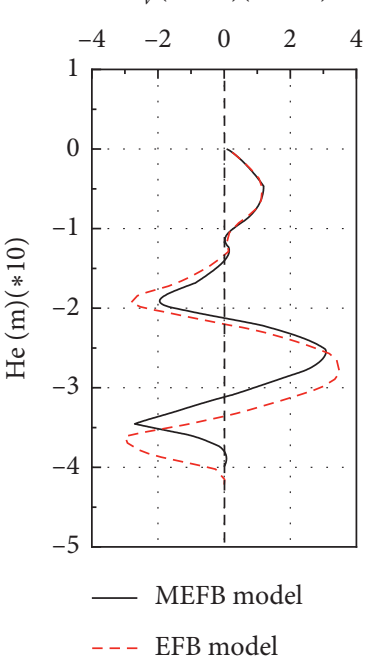

(c)

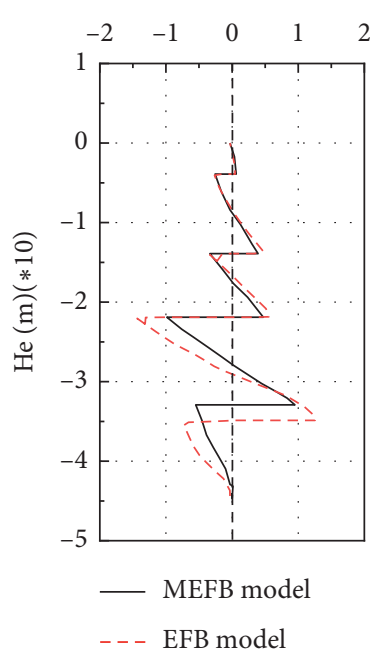

(d)

FIGURE 16: Comparison of the wall deformation using MEFB and EFB methods.

TABLE 6: Calculation results of MEFB method and EFB method.

\begin{tabular}{lcccccc}
\hline Method & $\delta_{d, m}(\mathrm{~mm})$ & $+M_{V, m}(\mathrm{kN} . \mathrm{m})$ & $-M_{V, m}(\mathrm{kN} . \mathrm{m})$ & $+F_{S, m}(\mathrm{kN})$ & $-F_{S, m}(\mathrm{kN})$ & $A_{S}\left(\mathrm{~mm}^{2}\right)$ \\
\hline EFB & 29.36 & +3740 & -3117 & +1322 & -1053 & 10842 \\
MEFB & 18.16 & +3185 & -2703 & +950 & -987 & 9050 \\
\hline
\end{tabular}

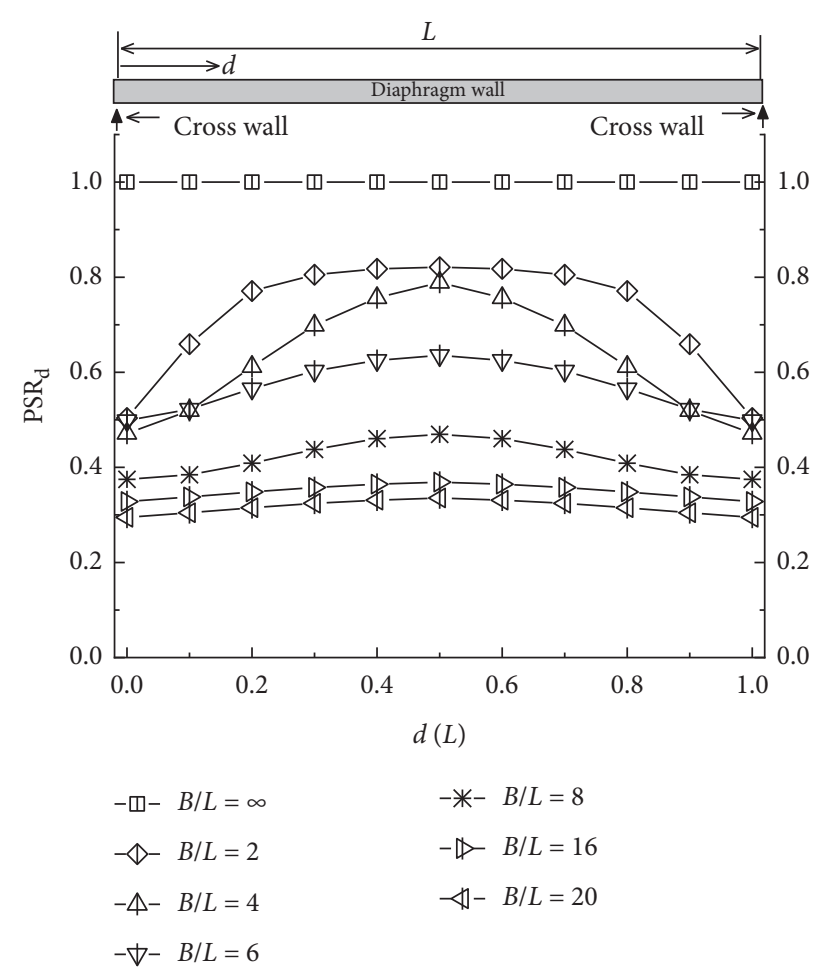

Figure 17: Relationship between $\operatorname{PSR}_{d}$ and the cross wall interval.

5.3. Effect of the Cross Wall Arrangement. Under the condition that the number of the bays was determined, the forms of 8 vertical bays and 8 horizontal bays were designed to study the effect of the cross wall arrangement. Figure 19 plots the values at the midline of two cross walls under two different cases. 


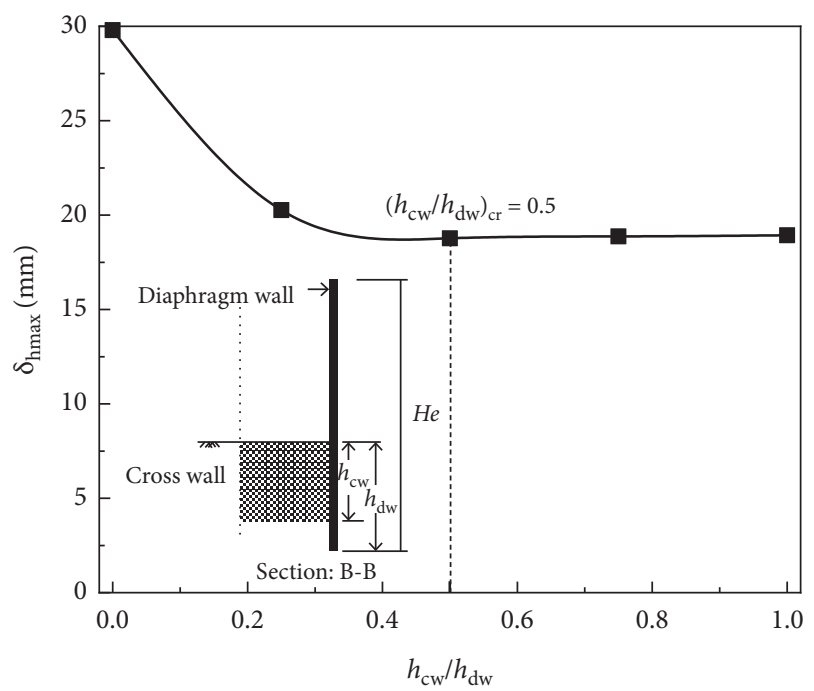

FIGURE 18: Relationship between $\mathrm{PSR}_{d}$ and the cross wall embedding depth.

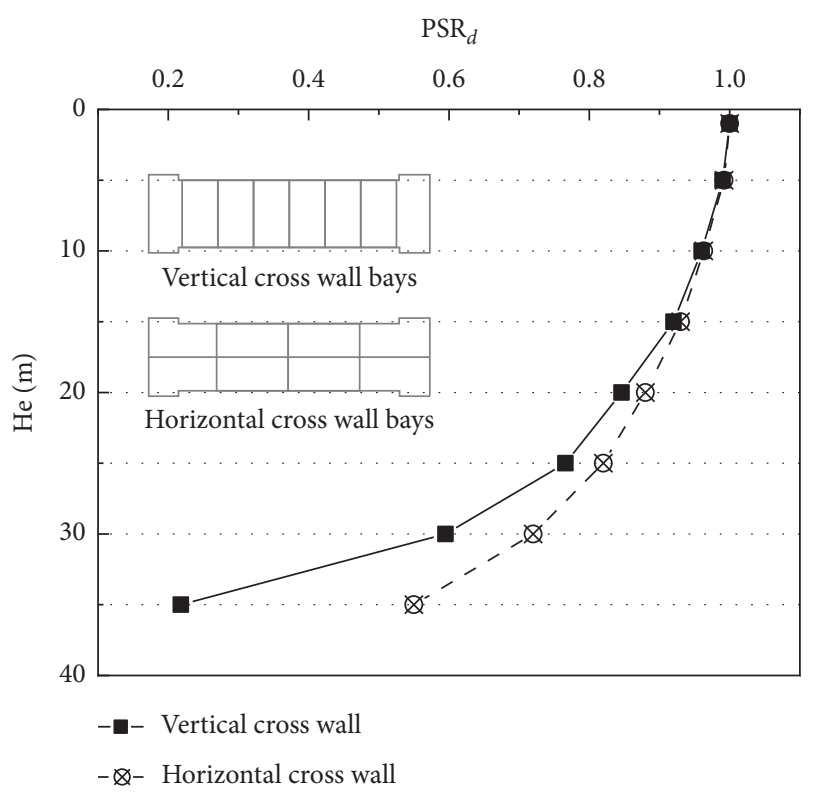

FIGURE 19: Relationship between $\mathrm{PSR}_{d}$ and the arrangement of the cross wall.

Above $\mathrm{GL}+15 \mathrm{~m}$, the $\mathrm{PSR}_{d}$ values were approximately equal to 1 under two cases, but under GL-20 m, both values were decreased prominently. Moreover, the $\mathrm{PSR}_{d}$ values of the vertical cross wall arrangement reduced faster compared with the horizontal arrangement. The value of the 8 vertical bays near the bottom (GL-36 m) was only 0.218 and reduced $60.3 \%$ compared with the 8 horizontal bays. Therefore, the vertical cross wall bays have a better counteraction on limiting the lateral wall deformation. When choosing the same space area, it was better to use vertical cross wall bays in practical engineering.

\section{Conclusions}

The modified Winkler foundation beam (MEFB method) presented in this paper can be used to analyze the deflection of the diaphragm-cross wall system during excavation. As shown in the figure, the predicted wall deflections using the MEFB method were similar to the $3 \mathrm{D}$ analysis results and field observations, but much smaller than the results calculated by the EFB method. According to the proposed method, the diaphragm wall deflection was the largest at the location where cross walls were installed and decreased with increasing $d$ to the cross wall, up to the midline of two cross walls. $\delta_{d, m}$ of the MEFB method was predicted to have a reduction of $40-60 \%$ compared to $\delta_{d, m}$ of the MEFB method.

$\mathrm{PSR}_{d}$ based on MEFB method was defined to optimize the parameters of the cross wall. Results showed that the critical interval ratio $(B / L)_{c r}=8$ and the critical embedded depth ratio $\left(h_{c w} / h_{d w}\right)_{c r}=0.5$ were more economical to control the diaphragm wall deformation. Furthermore, the wall deformation caused by vertical cross wall bays was much smaller than that of horizontal cross wall bays.

\section{Notation}

$H_{e}: \quad$ Excavation depth, $\mathrm{m}$

$\delta_{m}: \quad$ The maximum wall displacements, $\mathrm{mm}$

$\mu: \quad$ Poisson's ratio

$\varphi: \quad$ Internal friction angle, ${ }^{\circ}$

$\gamma: \quad$ Density of the soil, $\mathrm{kN} / \mathrm{m}^{3}$

$c$ : Cohesion, $\mathrm{kPa}$

$d$ : Distance to the cross wall, $\mathrm{m}$

$E_{w}: \quad$ Elastic modulus of diaphragm wall, $\mathrm{Pa}$

$E_{\mathrm{cW}}$ : Elastic modulus of cross wall, $\mathrm{Pa}$

$t_{w}$ : Thickness of diaphragm wall, $\mathrm{m}$

$t_{\mathrm{cw}}$ : Thickness of cross wall, $\mathrm{m}$

$\alpha: \quad$ Reduction coefficient related to support relaxation

A: $\quad$ Cross-sectional area, $\mathrm{m}^{2}$

$B: \quad$ Excavation width, $\mathrm{m}$

$I_{w}: \quad$ Inertia moment of diaphragm wall, $\mathrm{m}^{4}$

$K_{\mathrm{cw}}$ : Unit equivalent stiffness of simply supported beam, $\mathrm{N} / \mathrm{m}^{2}$

$K_{w, d}$ : Unit equivalent stiffness of fixed-end beam at a location $d$ away from cross wall, $\mathrm{N} / \mathrm{m}^{2}$

$K_{e, d}: \quad$ Unit equivalent stiffness of diaphragm-cross wall at a location $d$ away from cross wall, $\mathrm{N} / \mathrm{m}^{2}$

$L: \quad$ Cross wall interval, $m$

$L_{\mathrm{cw}}$ : Length of the cross wall, $\mathrm{m}$

$K_{h}$ : $\quad$ Passive earth spring stiffness, $\mathrm{N} / \mathrm{m}$

$q$ : $\quad$ Earth pressure per unit depth, $\mathrm{N}$

$\delta_{d}$ : Deformation of the diaphragm-cross wall system, $\mathrm{mm}$

$\delta_{d}$ : $\quad$ Deformation of the simply supported beam, mm

$\Delta \delta_{d}$ : Deformation of the fixed beam at any location of $d, \mathrm{~mm}$

$m$ : $\quad$ Proportional coefficient of base bed coefficient, $\mathrm{m}^{4}$

$a, b$ : Calculated spacing of the passive soil spring, $\mathrm{m}$

$h$ : Distance from the calculating point to the pit bottom, $m$

$K_{d}: \quad$ Total stiffness of passive zone $\mathrm{N} / \mathrm{m}$

$\Delta \delta_{d, \mathrm{me}}$ : Maximum lateral deformation of diaphragm wall on various sections of MEFB method, mm

$\delta_{h, \mathrm{ps}}: \quad$ Maximum lateral deformation of diaphragm wall on the plane strain ratio calculation method, $\mathrm{mm}$ 
$h_{\mathrm{cw}}$ : Cross wall embedding depth, $\mathrm{m}$

$h_{\text {Dw }}$ : Diaphragm wall embedding depth, $m$

$M_{v, m}$ : Diaphragm wall bending moment

$F_{S, m}: \quad$ Diaphragm wall shear force

$A_{S}: \quad$ Diaphragm wall reinforcement area.

\section{Data Availability}

The data used to support the findings of this study are available from the corresponding author upon request.

\section{Conflicts of Interest}

The authors declare that they have no conflicts of interest.

\section{Authors' Contributions}

CQJ and GHW conceived the idea of the study. BL and NNL analyzed most of the data and wrote the initial draft of the paper. RJ and GFL provided and collected the field monitoring data. All authors discussed the results and revised the manuscript.

\section{Acknowledgments}

This research was financially supported by the Ministry of Housing and Urban-Rural Development of the People's Republic of China (grant no. 2016-K4-056).

\section{References}

[1] M. S. Cheung, "A simplified finite element solution for the plates on elastic foundation," Computers \& Structures, vol. 8, no. 1, pp. 139-145, 1978.

[2] D. K. Nag and Y. K. Cheung, "Plates and beams on elastic foundations-linear and non-linear behaviour," Géotechnique, vol. 18, no. 2, pp. 250-260, 1968.

[3] Y. K. Cheung and O. C. Zinkiewicz, "Plates and tanks on elastic foundations-an application of finite element method," International Journal of Solids and Structures, vol. 1, no. 4, pp. 451-461, 1965.

[4] R. D. Cook, D. S. Malkus, M. E. Plesha, and R. J. Witt, Concepts and Applications of Finite Element Analysis, John Wiley \& Sons, Hoboken, NJ, USA, 2nd edition, 1984.

[5] R. L. Ruhl, T. F. Conry, and R. L. Steger, "Unbalanced response of a large rotor-pedestal-foundation system using an elastic half-space soil model," Journal of Mechanical Design, vol. 102, no. 2, pp. 311-319, 1980.

[6] L. S. Zhao, W. H. Zhou, F. Behzad, X. B. Li, and K. V. Yuen, “A dual beam model for geosynthetic-reinforced granular fill on an elastic foundation," Applied Mathematical Modelling, vol. 40, no. 21-22, pp. 9254-9268, 2016.

[7] V. Z. Vlasov, U. N. Leont'Ev, and T. Pelz, "Beams, plates and shells on elastic foundations," Translated from Russian by A. Barouch, Israel Program for Scientific Translations Jerusalem, Jerusalem, Israel, 2010.

[8] R. Jones and J. Xenophontos, "The Vlasov foundation model," International Journal of Mechanical Sciences, vol. 19, no. 6, pp. 317-323, 1977.
[9] C. V. G. Vallabhan and Y. C. Das, "Parametric study of beams on elastic foundations," Journal of Engineering Mechanics, vol. 114, no. 12, pp. 2072-2082, 1988.

[10] E. Winkler, Die Lehre von der Elastizitat und Festigkeit, Dominicus, Prague, Czech Republic, 1867.

[11] A. Lim, P.-G. Hsieh, and C.-Y. Ou, "Evaluation of buttress wall shapes to limit movements induced by deep excavation," Computers and Geotechnics, vol. 78, pp. 155-170, 2016.

[12] B. Wang, R. Fang, and Q. Wang, "Flexural behavior of fiberreinforced self-stressing concrete T-shaped composite beams," Advances in Civil Engineering, vol. 2020, pp. 1-17, Article ID 8810440, 2020.

[13] R. N. Hwang and Z. C. Moh, "Evaluating effectiveness of buttresses and cross walls by reference envelopes," Journal of Geoengineering, vol. 3, no. 1, pp. 1-11, 2008.

[14] E. H. Y. Leung and C. W. W. Ng, "Wall and ground movements associated with deep excavations supported by cast in situ wall in mixed ground conditions," Journal of Geotechnical and Geoenvironmental Engineering, vol. 133, no. 2, pp. 129-143, 2007.

[15] G. Zheng, Y. Wang, P. Zhang et al., "Performances and working mechanisms of inclined retaining structures for deep excavations," Advances in Civil Engineering, vol. 2020, no. 5, pp. 1-18, Article ID 1740418, 2020.

[16] S.-H. Wu, J. Ching, and C.-Y. Ou, "Predicting wall displacements for excavations with cross walls in soft clay," Journal of Geotechnical and Geoenvironmental Engineering, vol. 139, no. 6, pp. 914-927, 2013.

[17] J. J. Zheng, R. Zhang, L. Ding, Q. Chen, and D. Zhao, "Displacement control effects and parameter analysis of passive zone improvement of foundation pits," Chinese Journal of Rock Mechanics and Engineering, vol. 29, no. 5, pp. 1042-1051, 2010.

[18] P.-G. Hsieh, C.-Y. Ou, and Y.-L. Lin, "Three-dimensional numerical analysis of deep excavations with cross walls," Acta Geotechnica, vol. 8, no. 1, pp. 33-48, 2013.

[19] C.-Y. Ou, P.-G. Hsieh, and Y.-L. Lin, "A parametric study of wall deflections in deep excavations with the installation of cross walls," Computers and Geotechnics, vol. 50, pp. 55-65, 2013.

[20] C. Jiang, J.-L. He, L. Liu, and B.-W. Sun, "Effect of loading direction and slope on laterally loaded pile in sloping ground," Advances in Civil Engineering, vol. 2018, no. 4, pp. 1-12, Article ID 7569578, 2018.

[21] Y. Yang and H.-S. Yu, "A kinematic hardening soil model considering the principal stress rotation," International Journal for Numerical and Analytical Methods in Geomechanics, vol. 37, no. 13, pp. 2106-2134, 2013.

[22] F. Dengg, O. Zeman, K. Voit, and K. Bergmeister, "Fastening application in concrete using recycled tunnel excavation material," Structural Concrete, vol. 19, no. 2, pp. 374-386, 2018.

[23] C.-Y. Ou, D.-C. Chiou, and T.-S. Wu, "Three-dimensional finite element analysis of deep excavations," Journal of Geotechnical Engineering, vol. 122, no. 5, pp. 337-345, 1996. 